\title{
The EFFECT OF BIO SKIN FACADES ON DAYLIGHT AND THERMAL PERFORMANCE IN EDUCTIONAL SPACE
}

\author{
Gehad Ghonemy ${ }^{1}$, Hisham Sobh², Ahmed El Kordy ${ }^{3}$ \\ ${ }^{1}$ Department of Architecture, Nile Academy, Mansoura, Egypt \\ ${ }^{2}$ Department Of Architecture, Faculty of Engineering , Al- Azhar University, Cairo, Egypt \\ ${ }^{2}$ Department Of Architecture, Faculty of Engineering, Al- Azhar University, Cairo, Egypt \\ Received : 3 July 2021 Accepted: 10 September 2021
}

\begin{abstract}
Openings of external facades of the building is the element responsible for the perméabilite of natural lighting to the architectural space, as increased the percentage of openings for the external facade, greater the amount of daylight in the space, but it is accompanied by thermal gain inside the space. Therefore, the research focused on designing a simulated dynamics skin facade for the of opening and closing the gaps of the cactus plant when exposed to the sun, but the simulation is done indirectly according to the organization 3.8, which is an organization responsible for simulating nature in various fields[1]. As the dynamics of movement in the cactus plant to reduce the transpiration process in the plant for the ability to adapt and survive, while the dynamics of opening and closing in the simulated interface of the plant to reduce the heat gain with the distribution of the amount of light required during the educational space (200-500 lux) according to the Egyptian code and ASHRAE -55 [2], for the student's ability to adapt with in the space and perform his mental tasks. The skin facade was designing and the effect on the optical and thermal performance inside the space was measured using the Grasshopper-Rhino program, which is among the many available programs, but it allows the user to design a variable input model associated with it. Measure both the thermal and optical performance of the space using Diva, Honeybee to compare the thermal and optical performance before and after using skin facade was Mimic of nature. It was concluded that biomimetics contribute significantly to achieving thermal and visual comfort in educational spaces.
\end{abstract}
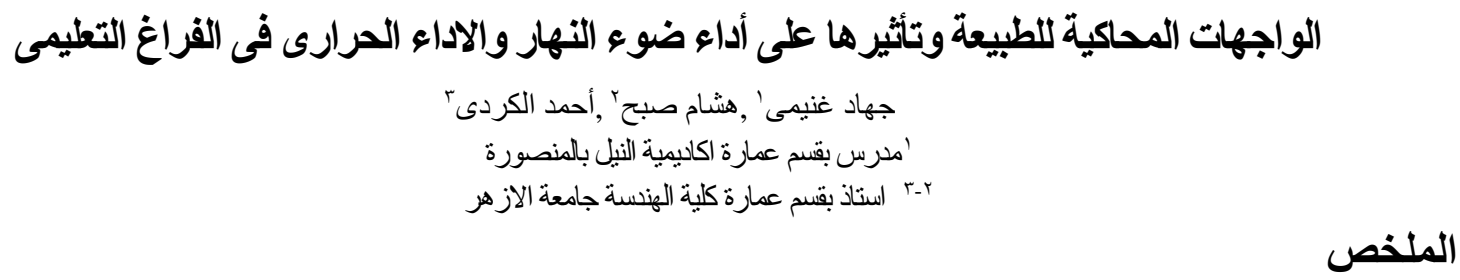

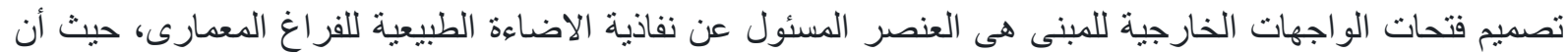

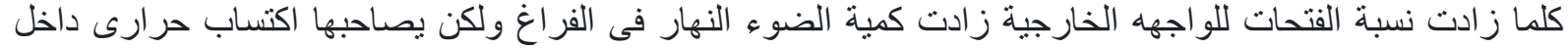

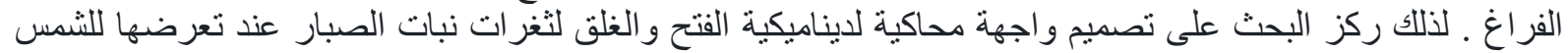




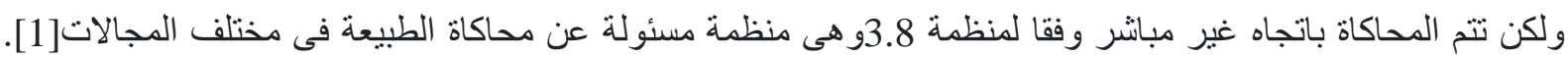

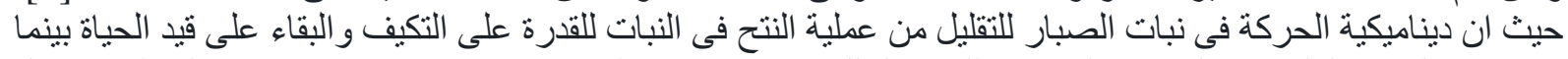

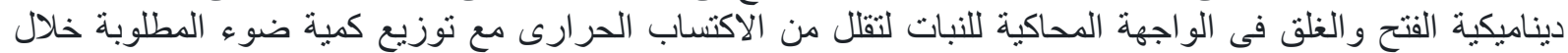

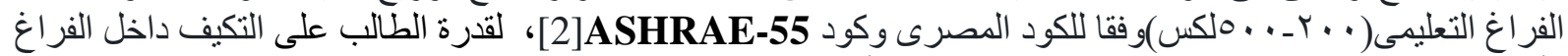

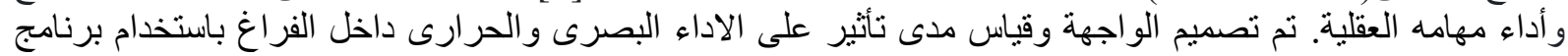
Grasshopper-Rhino،

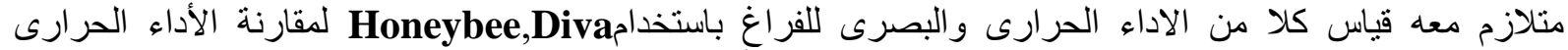
و البصرى قبل وبعد استخدام الو اجهة المحاكية للطبيعة.استتنج أن المحاكاة الحيوية تساهم بشكل كبير فى تحقيق الراحة الإنة الحر ارية والبصرية في الاماكن التعليمية.

الكلمات المفتاحية : الواجهات المحاكية للطبيعه،أداء ضوء النهار،الأداء الحرارى.

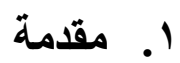

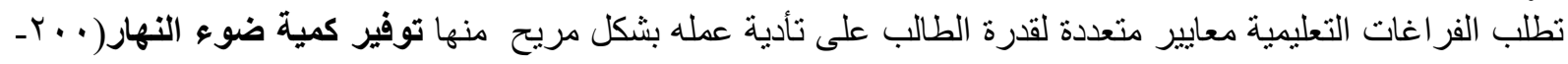

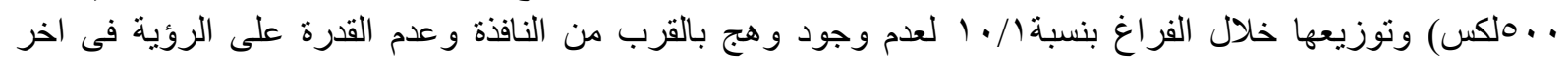

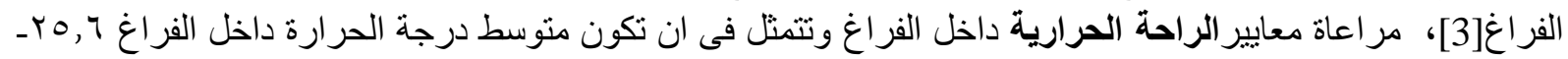

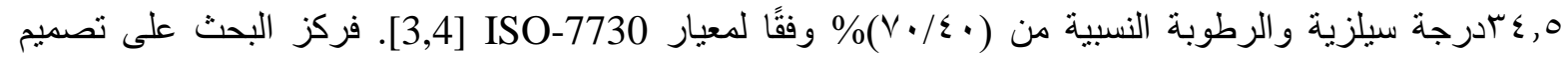

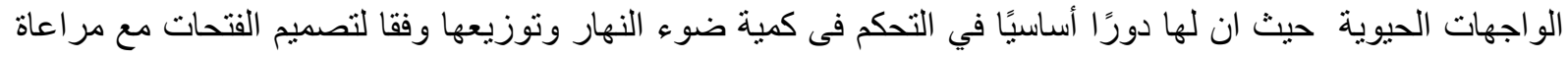

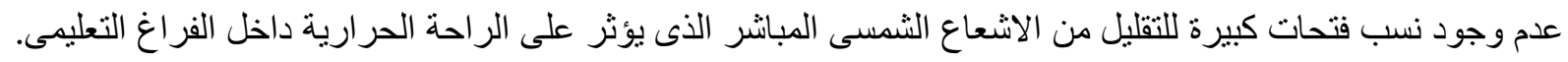

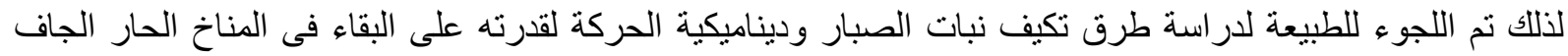

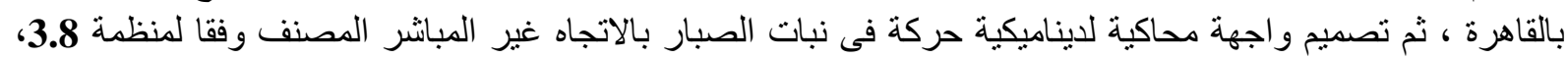

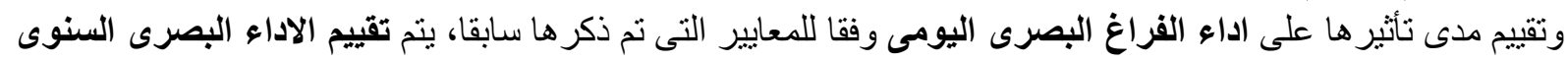

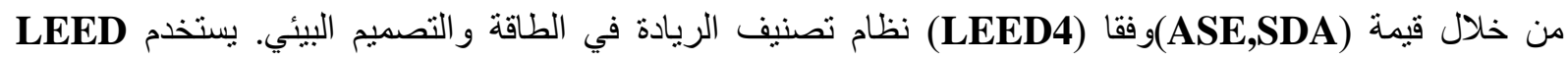
مقاييس مثل استقلالية ضوء النهار (DA=DAYLIGHT ATOUNMMY) هي النسبة المئوية لساعات العمل

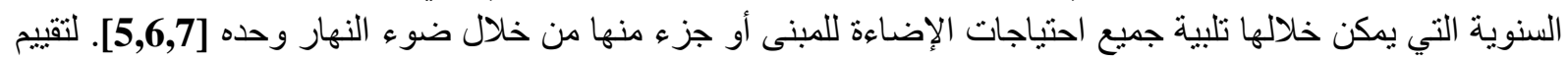
استقلالية ضوء النهار (DA) ، يتم تحديد مقياسان هما: (SDA= SPITIAL DAYLIGHT ATOUNMY) هو (لو

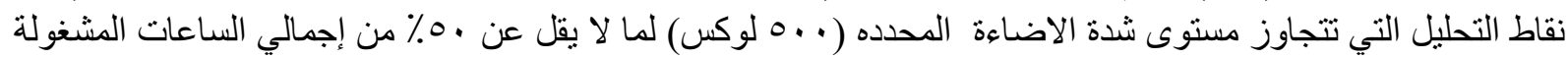

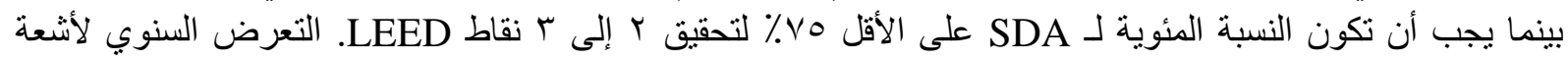
الثمس (ASE= ANNUAL SUN EXPOUSRE) يحسب هذا المقياس النسبة المئوية لنتائج التحليل التي تتجاوز

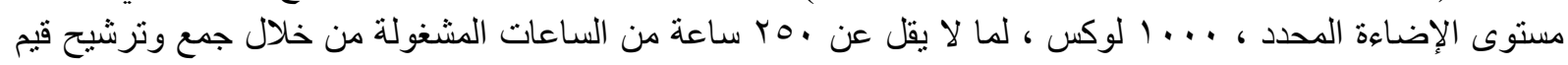

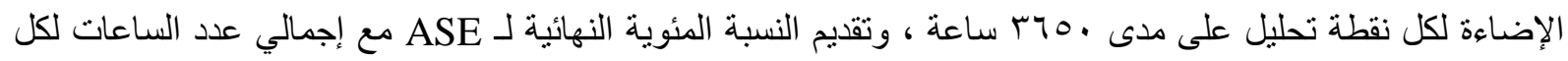

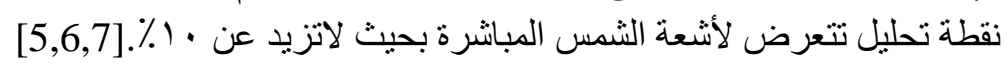

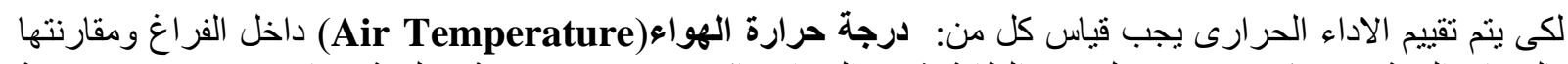

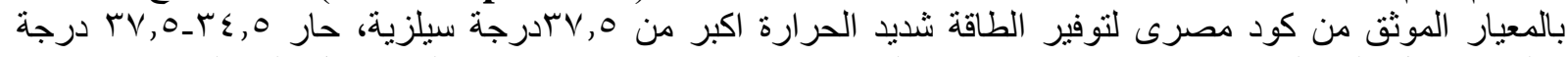

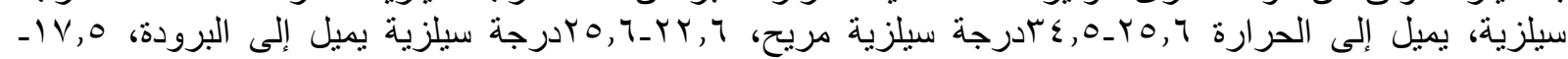

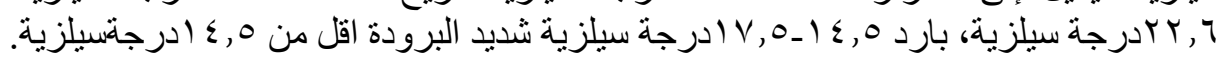

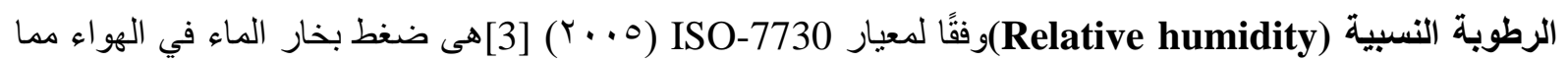

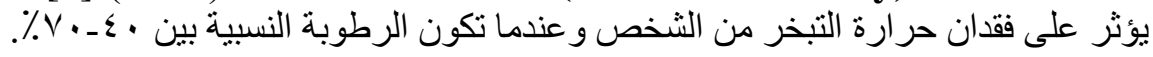

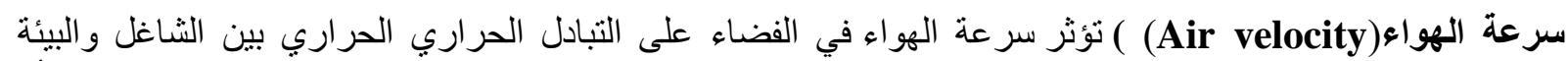

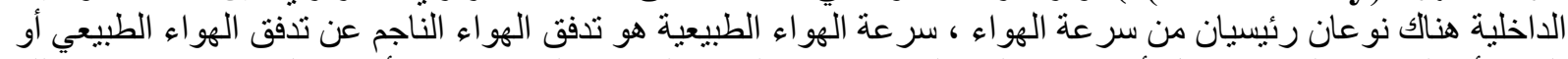

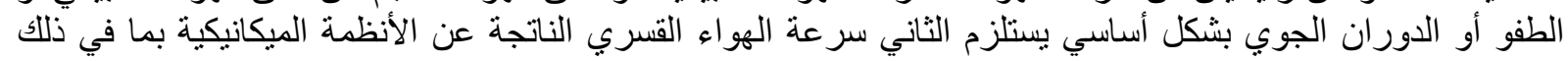

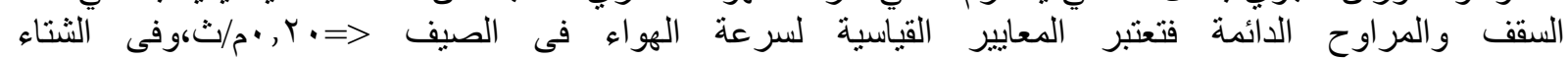

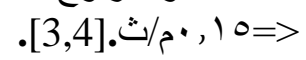


ثم رصد النتائج على موقع (CPE=CENTER FOR THE BUILT ENVIRONMENT) لمعرفة مدى العقى تحقيق الغلاف فى تحقيق الر احة الحر ارية,وفقا لمعايير ASHRAE 55 و

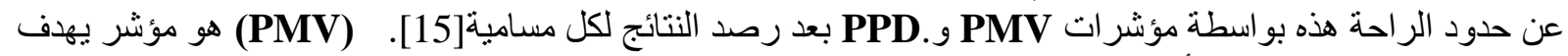

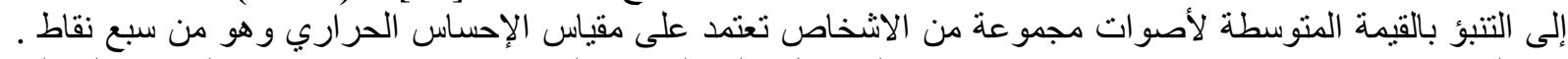

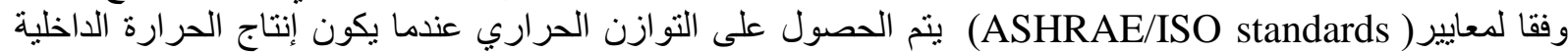

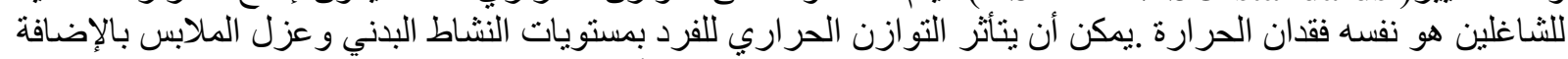

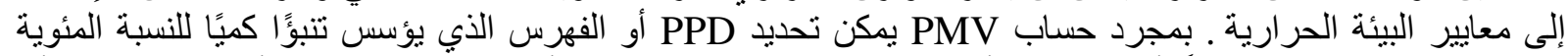

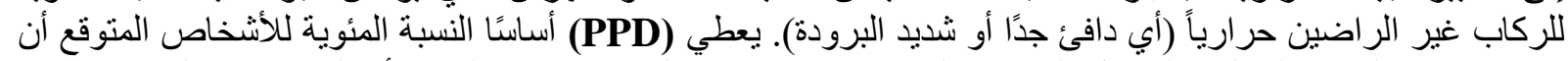

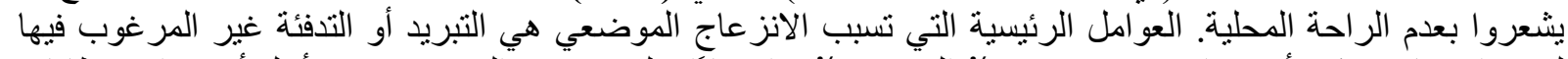

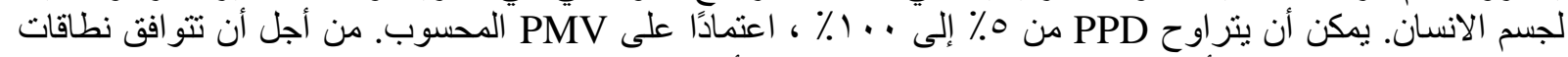

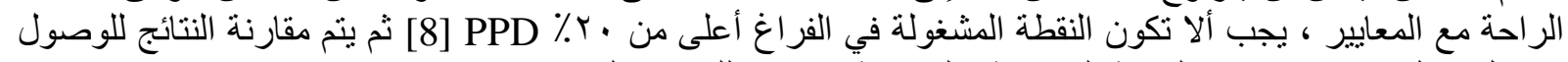

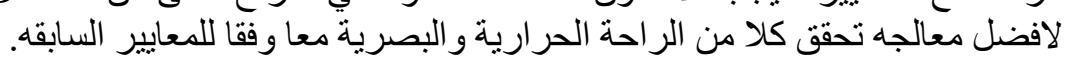

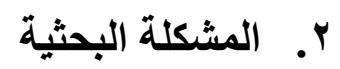

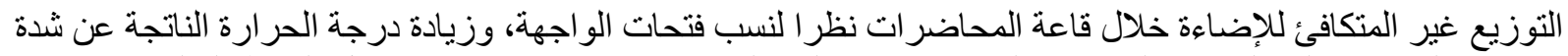

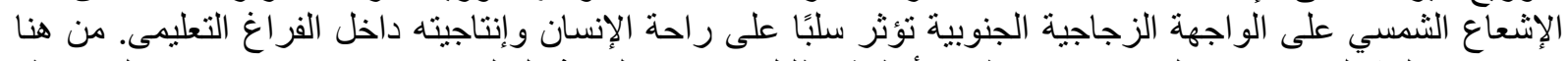

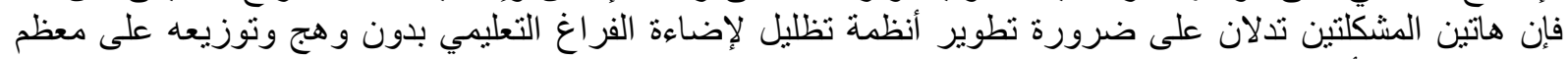

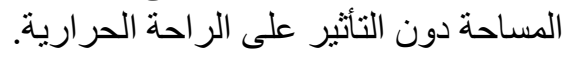
r. أب مدف البحث

تحقيق الراحة البصرية و الحرارية معا داخل الفراغ التعليمى من خلال تصميم واجهة خارجية محاكية لديناميكية نبات الصبار. ع. ـ منهجية البحث تنقسم المنهجية الى ثلاث مراحل :- الم الماه

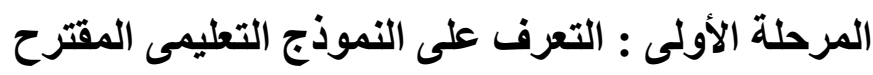

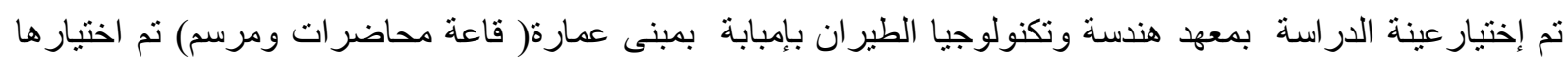

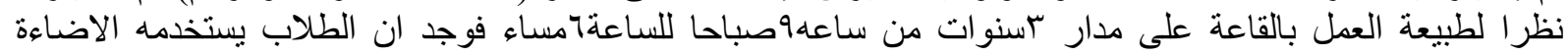

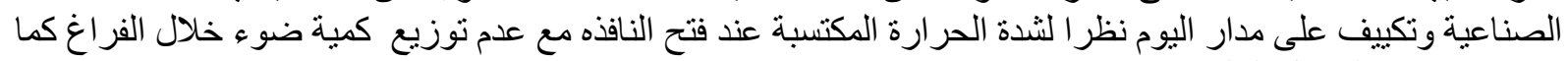

جدول( (1)يوضح بيانات الفراغ الذى يتم عليه الدراسة هو موضح فى الجدول التالى.

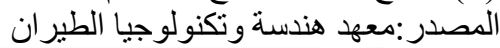
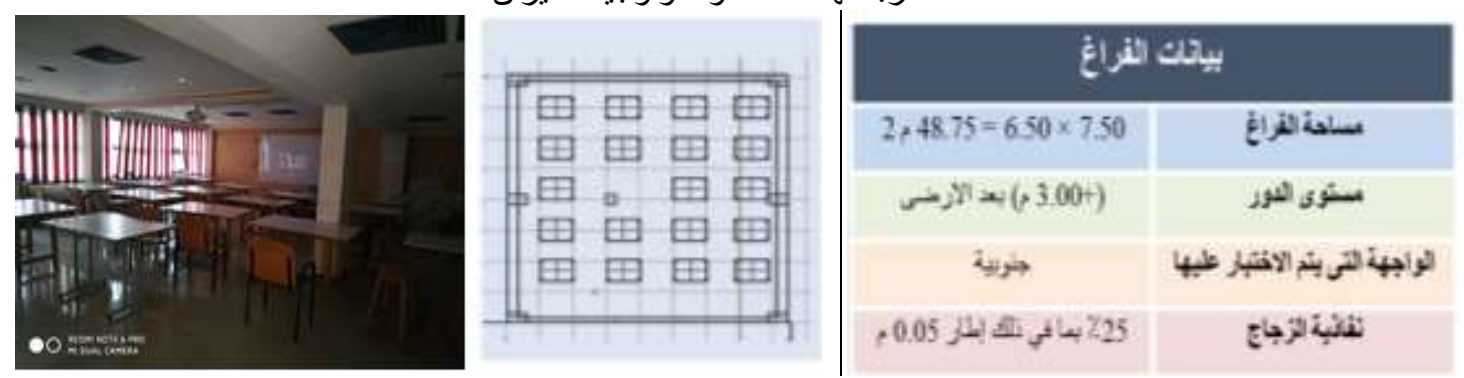

المرحلة الثانية: تعريف خطوات البرنامج المستخدم فى المحاكاة وتقييم الاداء

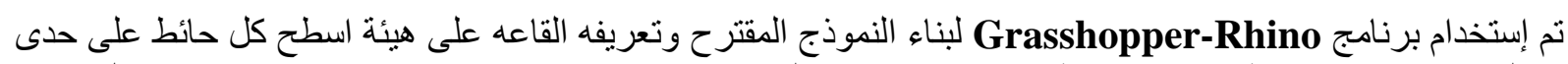

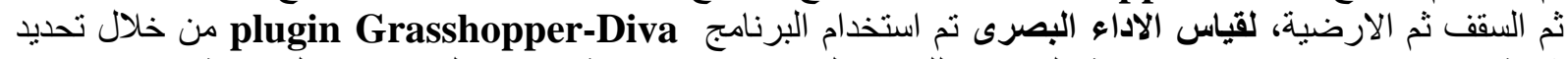

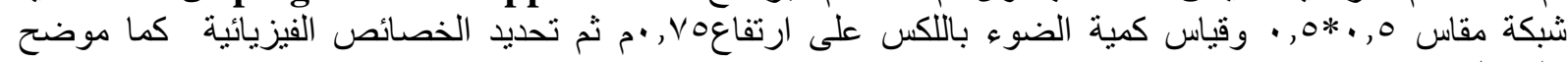
بالجدول]9 جدول(r) يوضح الخصائص الفيزيائية المستخدمة بالفر اغ للمحاكاة البصرية قبل وبعد المعالجة 
الواجهات المحاكية للطبيعة وتثثيرها طى أداء ضوء النهار والاداء الحرارى فى الفراغ التعليمى

المصدر:الكود المصرى لتوفير الطاقة

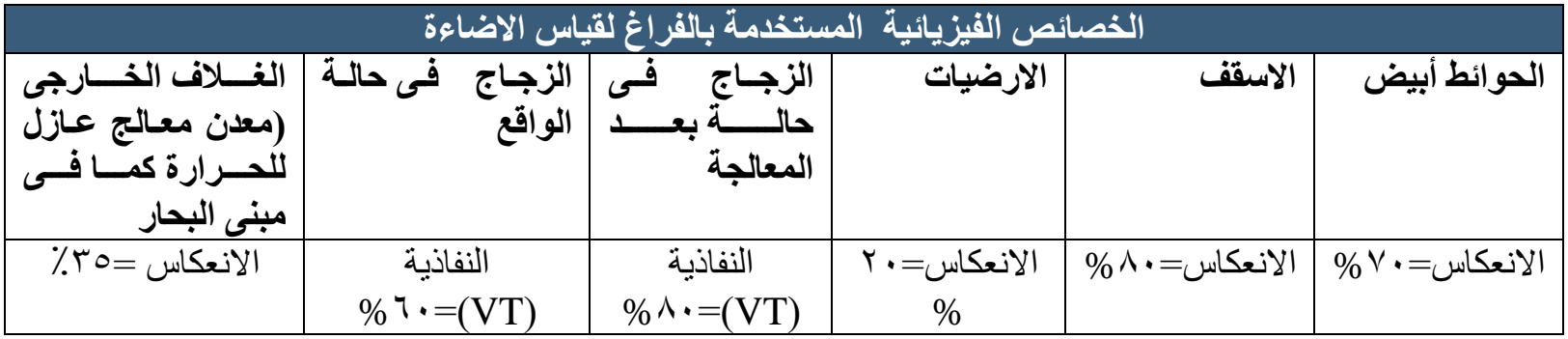

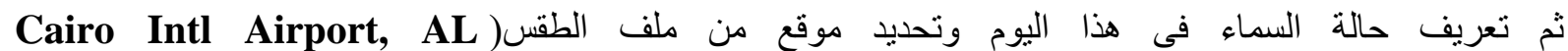
(Qahirah,EGY.etmy

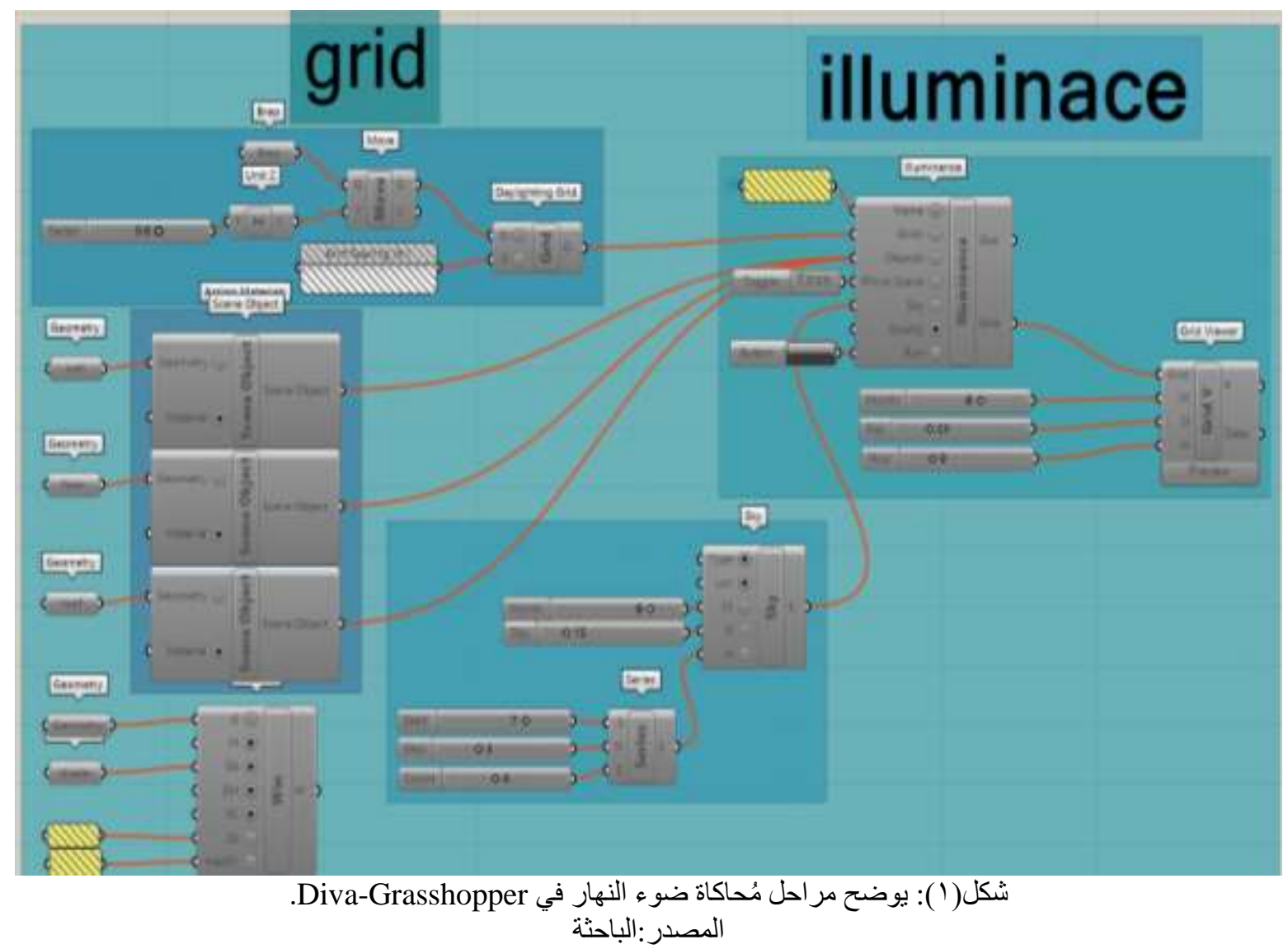

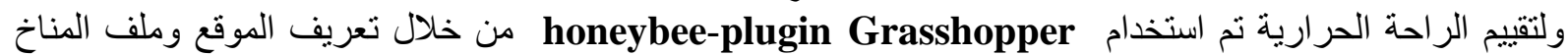

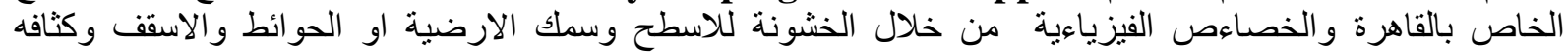
و التوصيل الحر ارى من خلال الكود المصرى لتوفير الطاقة [3,4 كما هو موضح فئنح في الثكل(2). 
الواجهات المحاكية للطبيعة وتتثيرها على أداء ضوء النهار والاداء الحرارى فى القراغ التعليمى

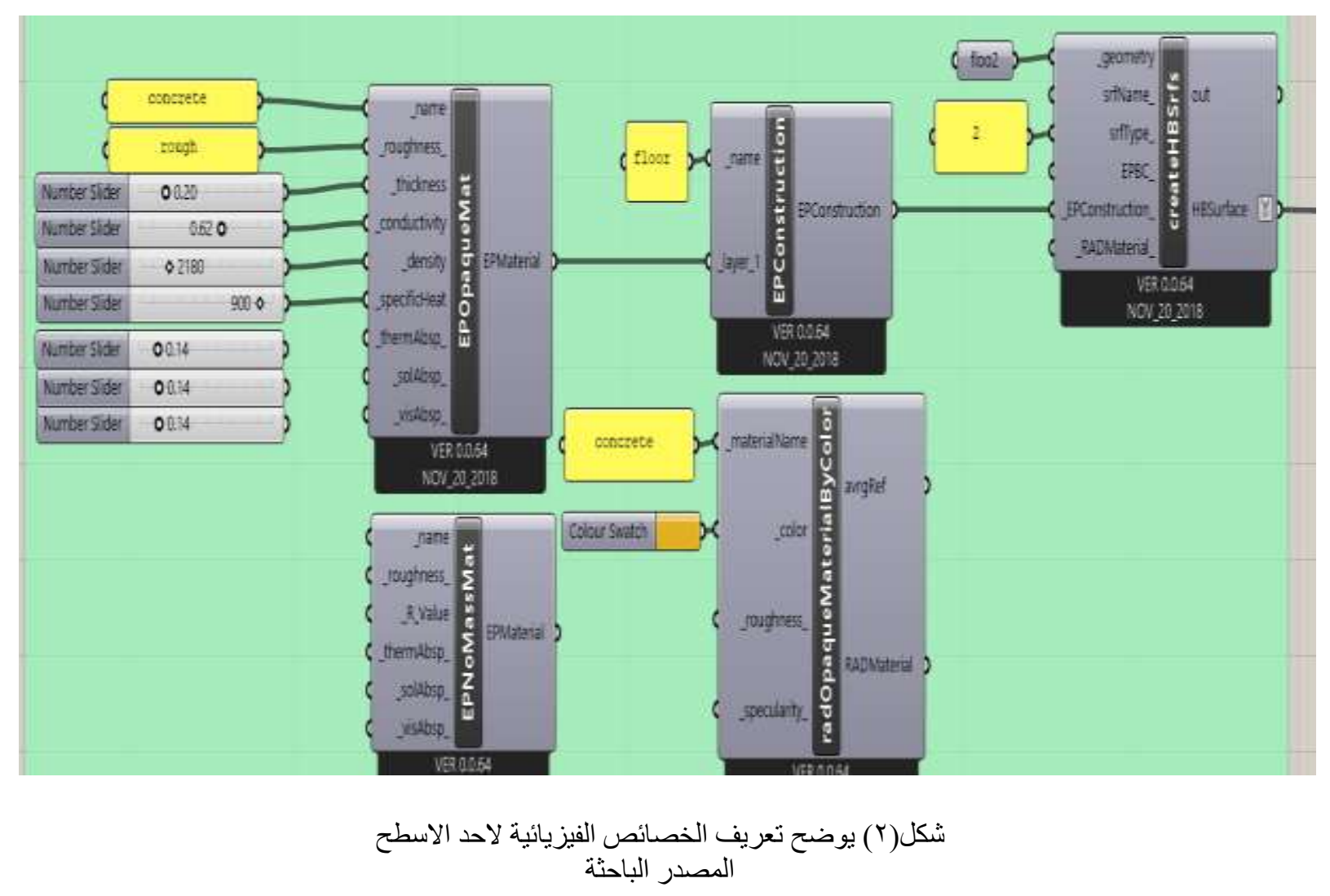

ثم تجميع الاسطح بمواد تشطيبها من خلال اداة تعريف الفراغ ثم عمل مرحلة تشغيل ملف الطقس (Cairo Intl) و تحديد يوم (19/N/10, Airport, AL Qahirah,EGY.epw) هذا اليوم أثد درجة حر ارة ناتج من در اسة المناخ وتوصيله بالفر اغ المجمع ثم قيام بمرحلة تشغيل مرحلة محاكاة الأداء. 
الواجهات المحاكية للطيعة وتتثيرها على أداء ضوء النهار والاداء الحرارى فى الفراغ التطليمى

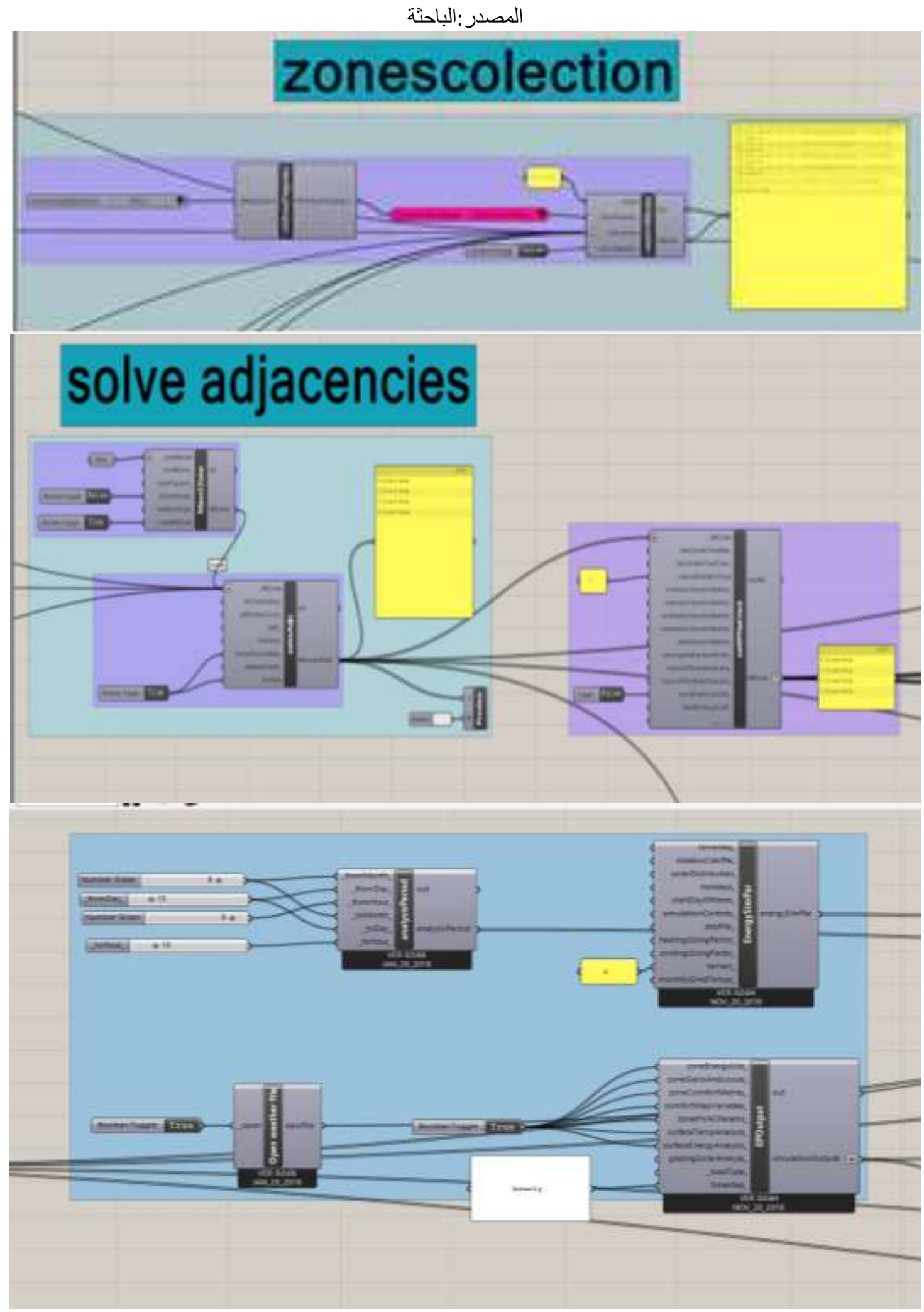

تجميع الاسطح لتصريف الفراغ 


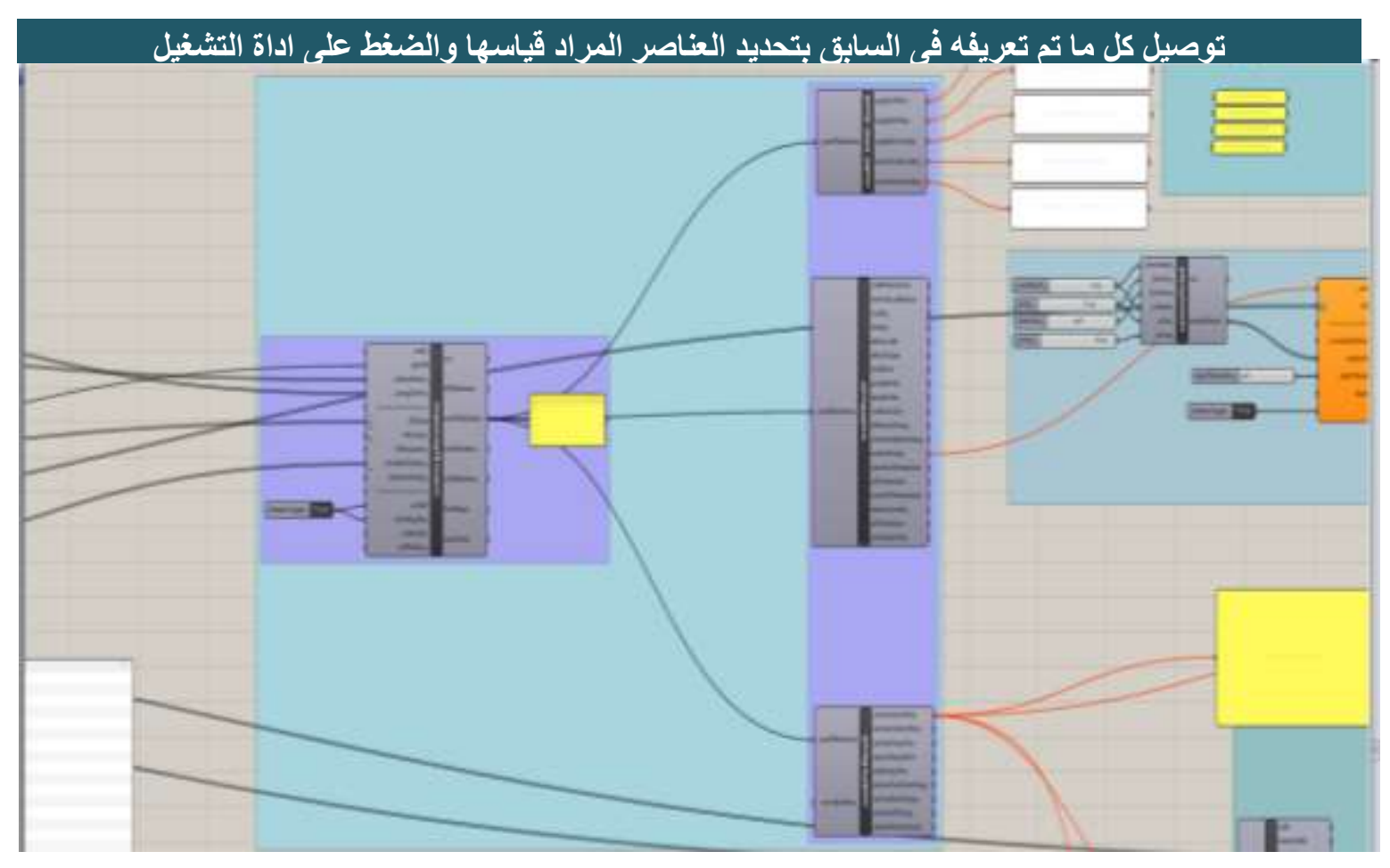

نتائج محاكاة ضوء النهار والحرارة بإستخدام الحاسوب قبل المعالجة

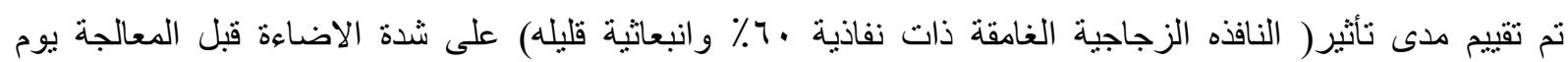

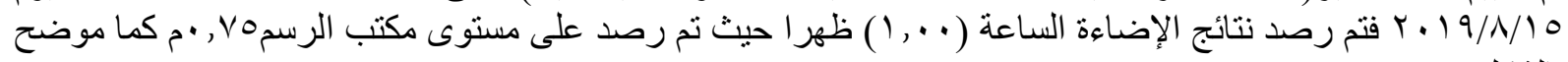

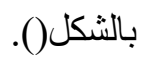

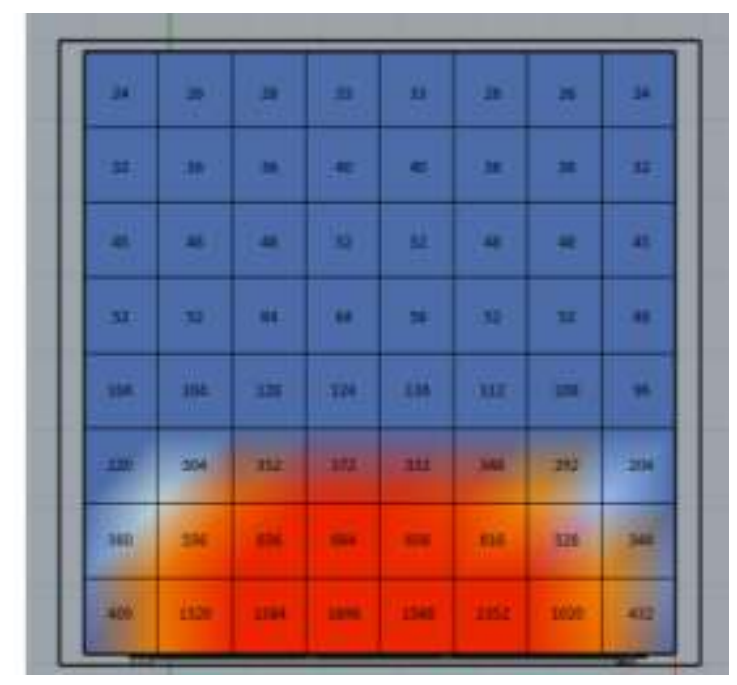

شكل(r) يوضح نتائج الاضـاءة الناتجة من المحاكاة الحاسوبية المصدر الباحثة

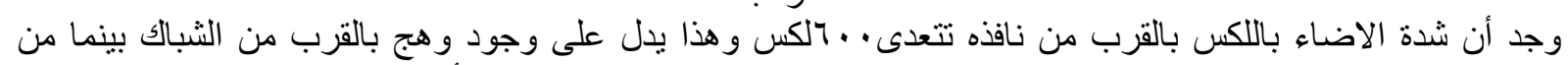

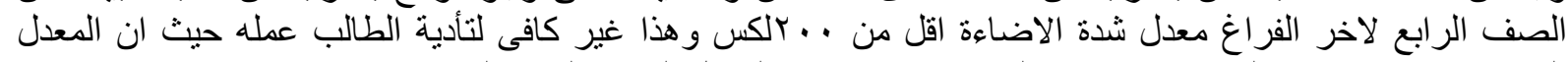

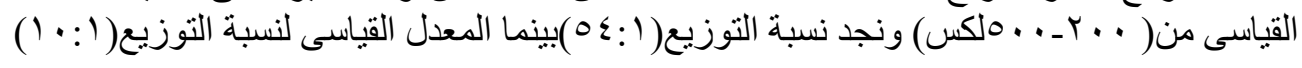

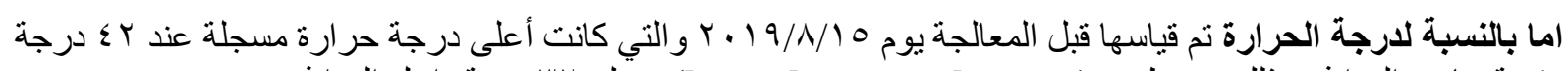

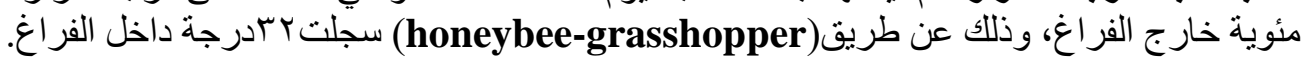




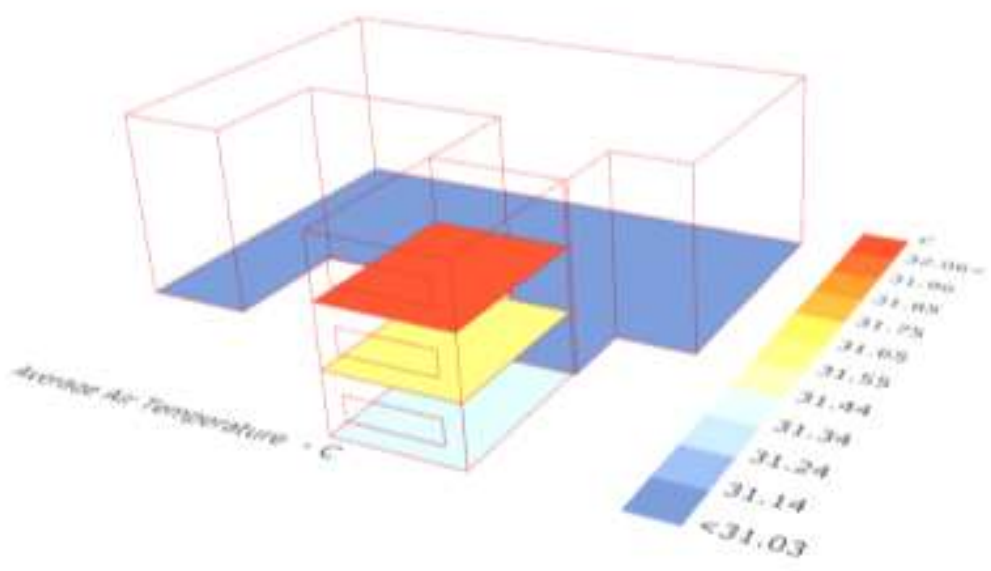

\section{شكل(§) يوضح نتيجة متوسط الحر ارة بالفر اغ قبل المعالجة \\ المصدر:الباحثة المبرة}

من خلال النتائج السابقة وجد ضرورة تصميم غلاف خارجى للواجهة لتقليل الاشعاع الثمسى مع توزيع جيد للضوء داخل الفراغ.

\section{المرحلة الثالثة:دراسة تحليلية لنبات الصبار وتصميم الغلاف الخارجى}

تم دراسة ديناميكية الحركة لنبات الصبار من حيث الغلق و الفتح باستخدام المجهر الالكترونى (SEM)فتم مر اقبه ديناميكيـة

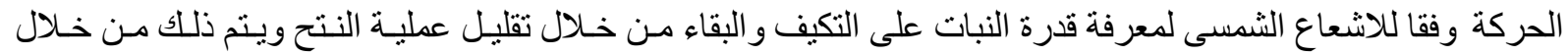

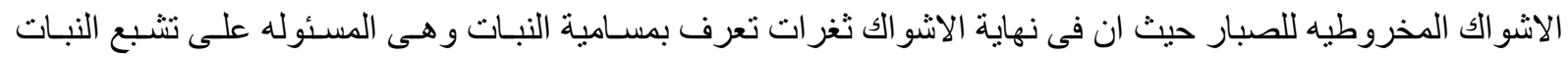

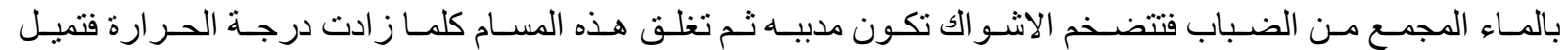

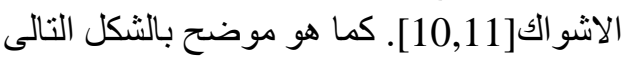

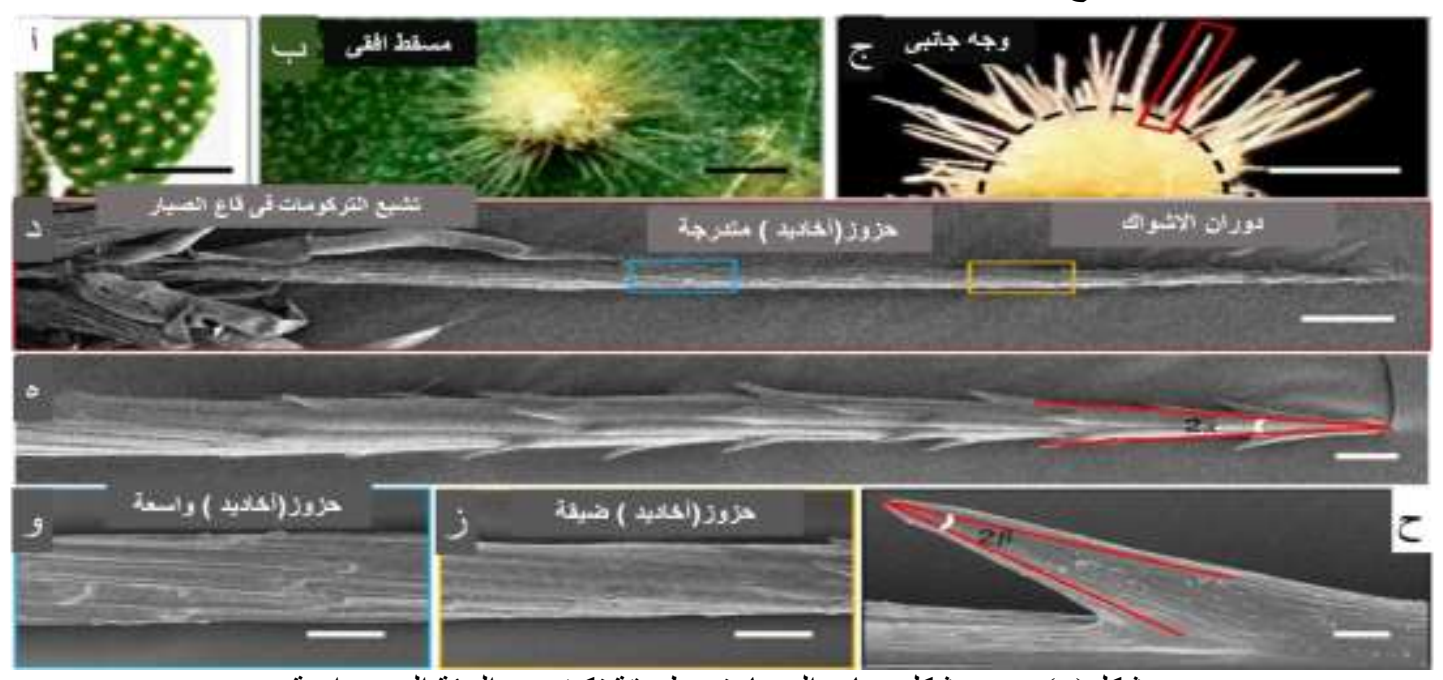

شكل(ه)يوضح شكل نبات الصبارفى طريقة تكيفه مع الييئة الصحر اوية

المصدر: (Jie Ju,Others,2012) .

تم اللجوء لتصميم الغلاف الخارجى للو اجهه الجنوبية الئحاكية أنثواك نبات الصبار من حيث ديناميكية الحركة لتقليل من

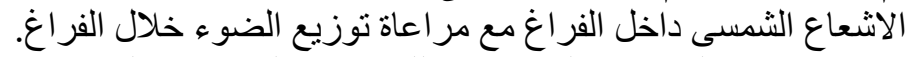

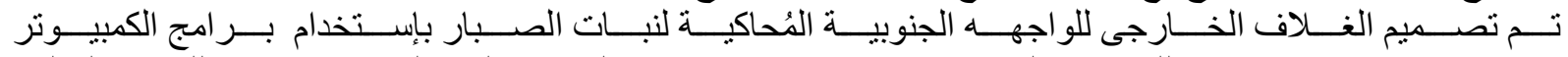

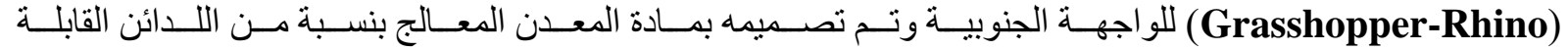

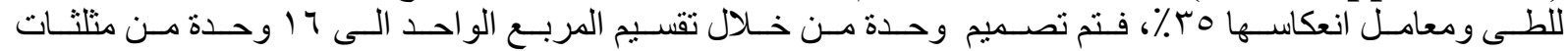

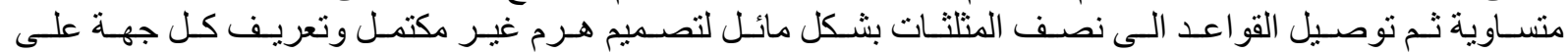

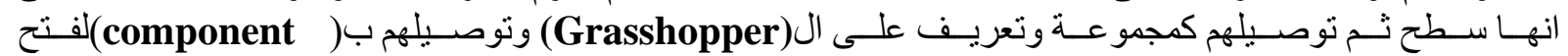

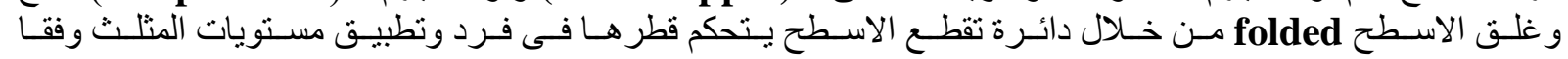




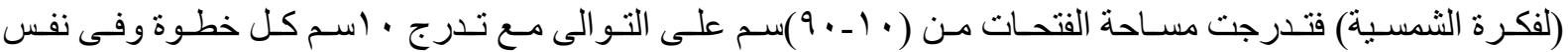

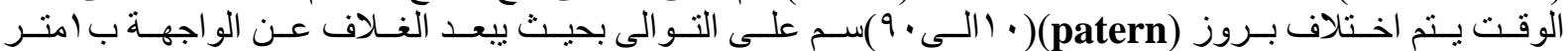
و عمق الغلاف • وسم، لتقييم الر احة البصرية والحر ارية على حد سو اء، كما هو موضح في الجدول التالى.

جدول(ع) تصميم الو اجهة المحاكية لنبات الصبار بإستخدام Grasshopper المصدر:الباحثة
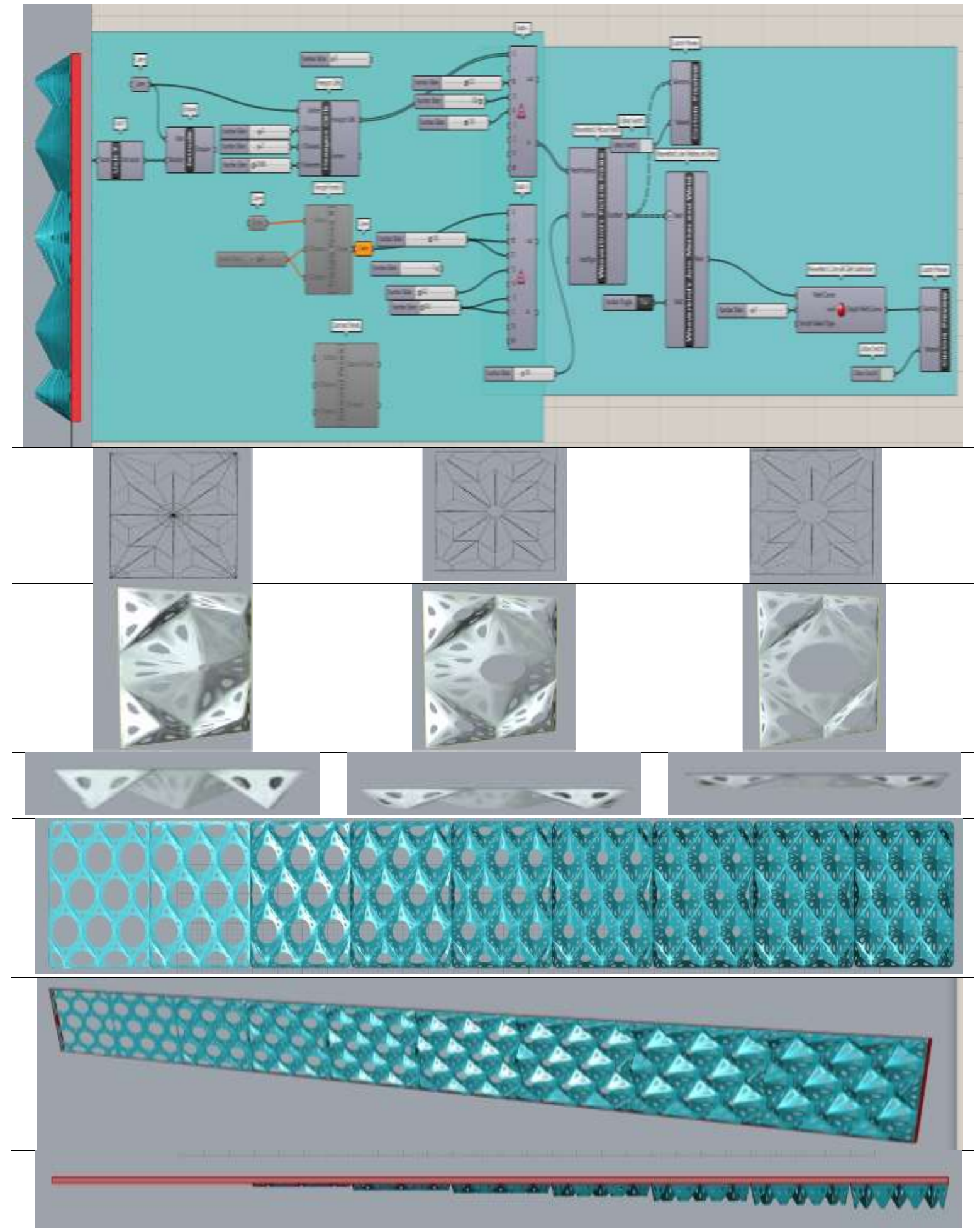

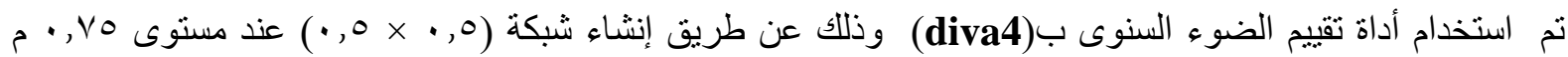

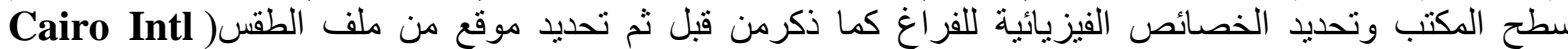

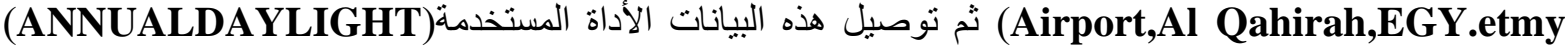




\section{الواجهات المحاكية للطييعة وتثلثيرها طلى أداء ضوء النهار والاداء الحرارى فى القراغ التعليمى}

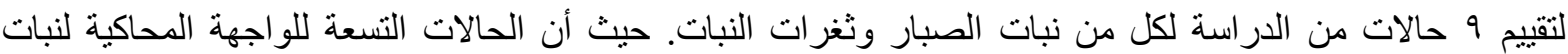

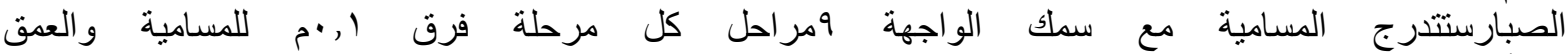

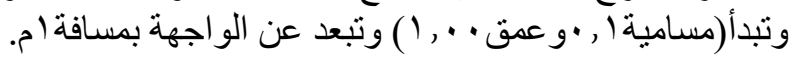

$$
\text { جدول(0) يوضح بيانات الغلاف الخارجى للو اجهة البهة }
$$

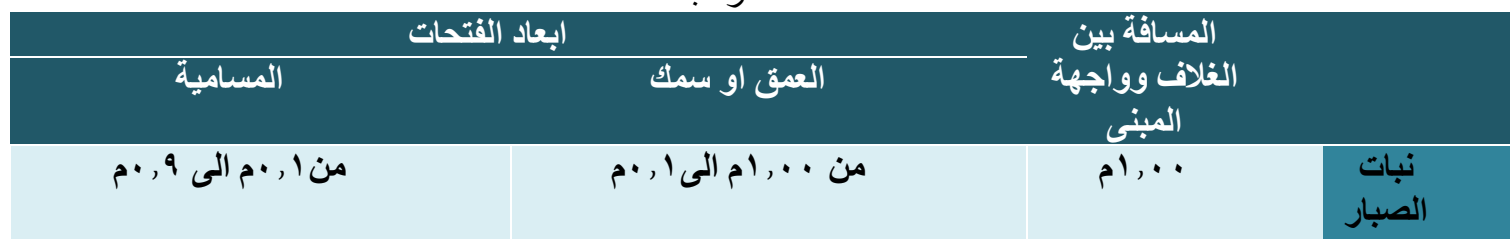

جدول(†) بيانات الإشعاع التي تم تعيينها لمقياس sDA و Daylight Availability.

المصدر :

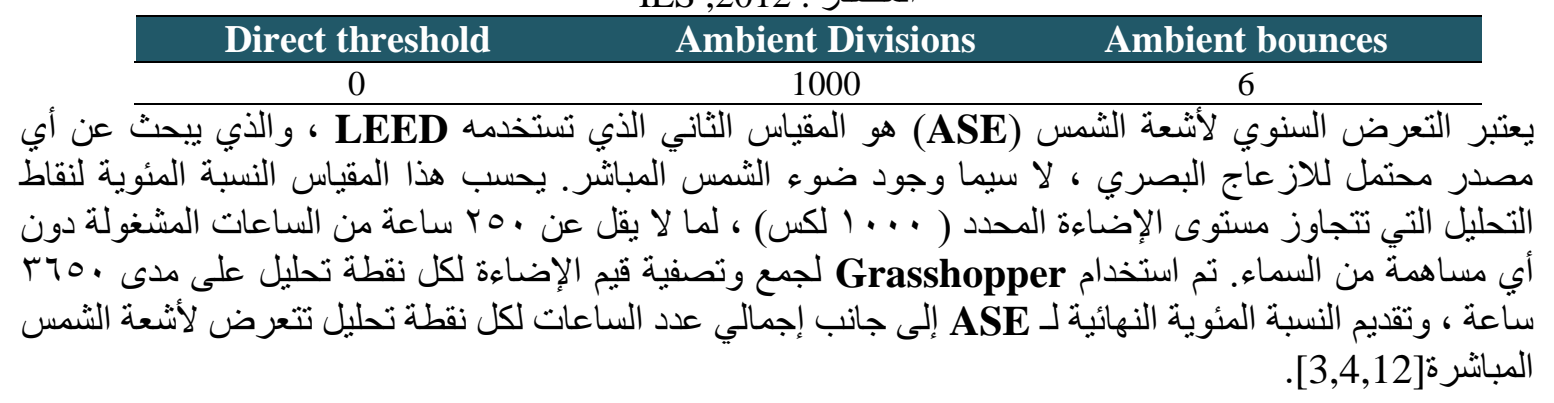

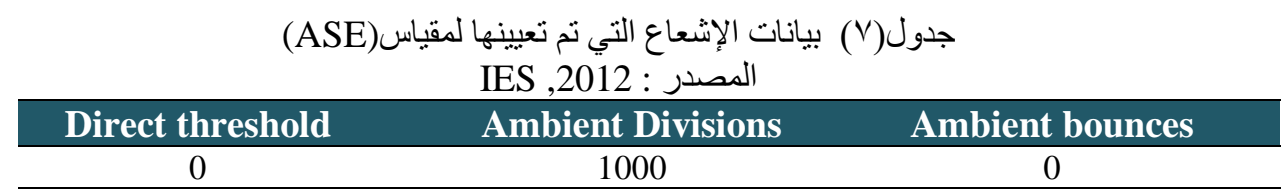

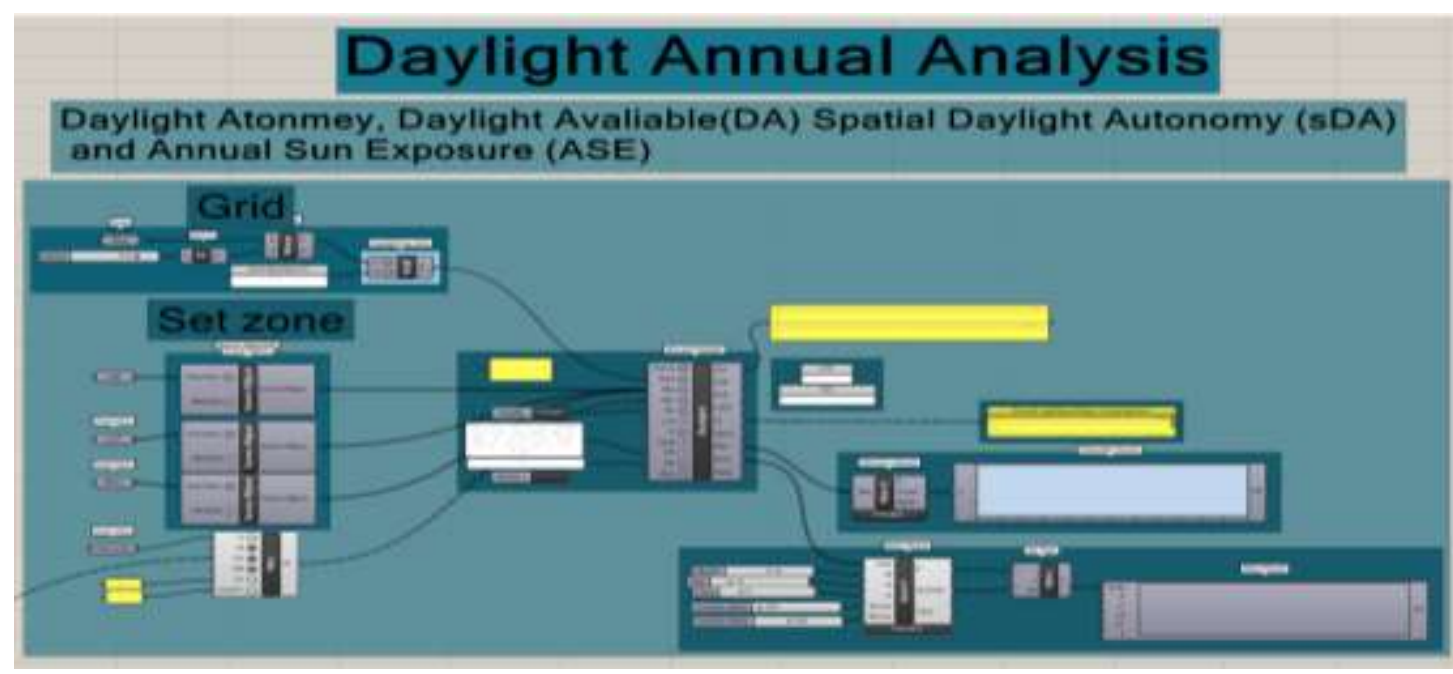

$$
\text { شكل(0)يوضح برمجه تقبيم السنوى لاداء ضوء النهار }
$$

•. ت نتائج تقييم أداء سنوى ضوء النهار قبل وبعد المعالجه

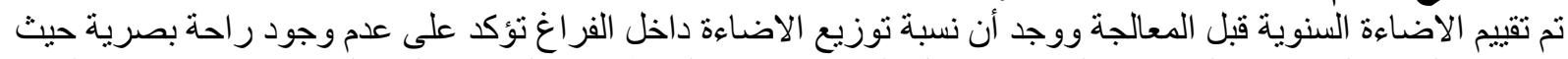

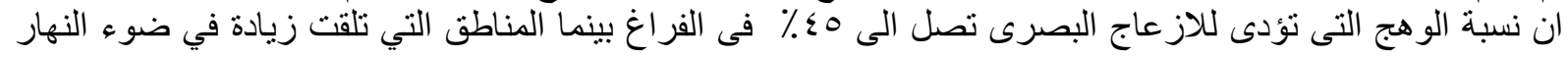




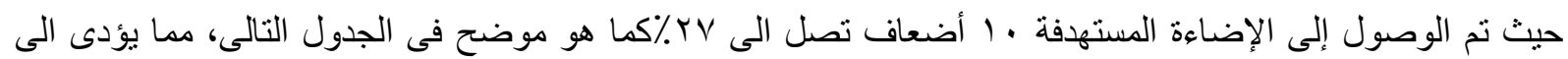

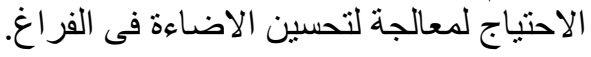
جدول(^) يوضح نتائج الأداء البصرى قبل المعالجة خلال العام وفقا لمقاييس الضوء الديناميكى المصدر :الباحثة

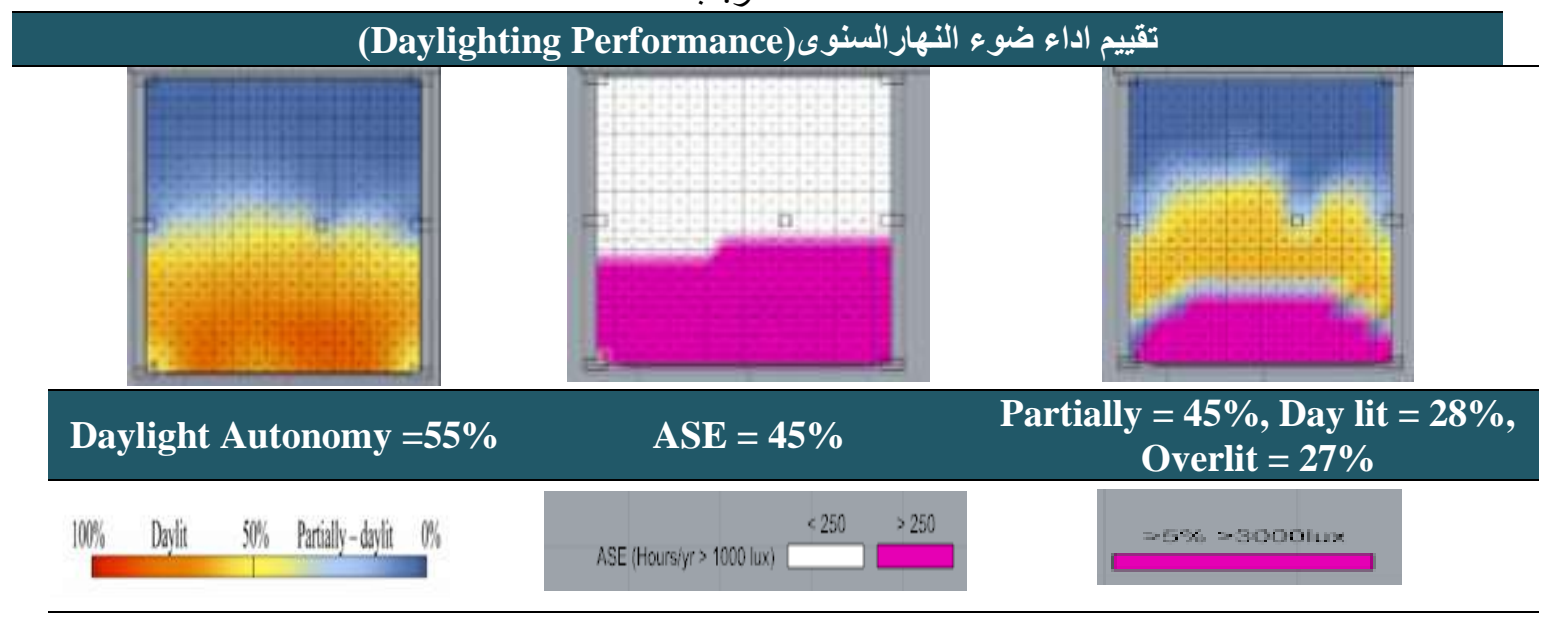

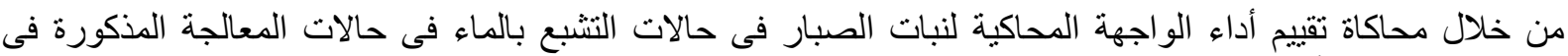

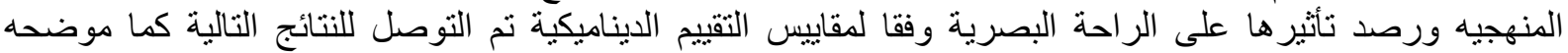

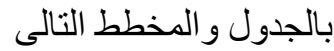


الواجهات المحاكية للطييعة وتثليرها على أداء ضوء النهار والاداء الحرارى فى القراغ التعليمى

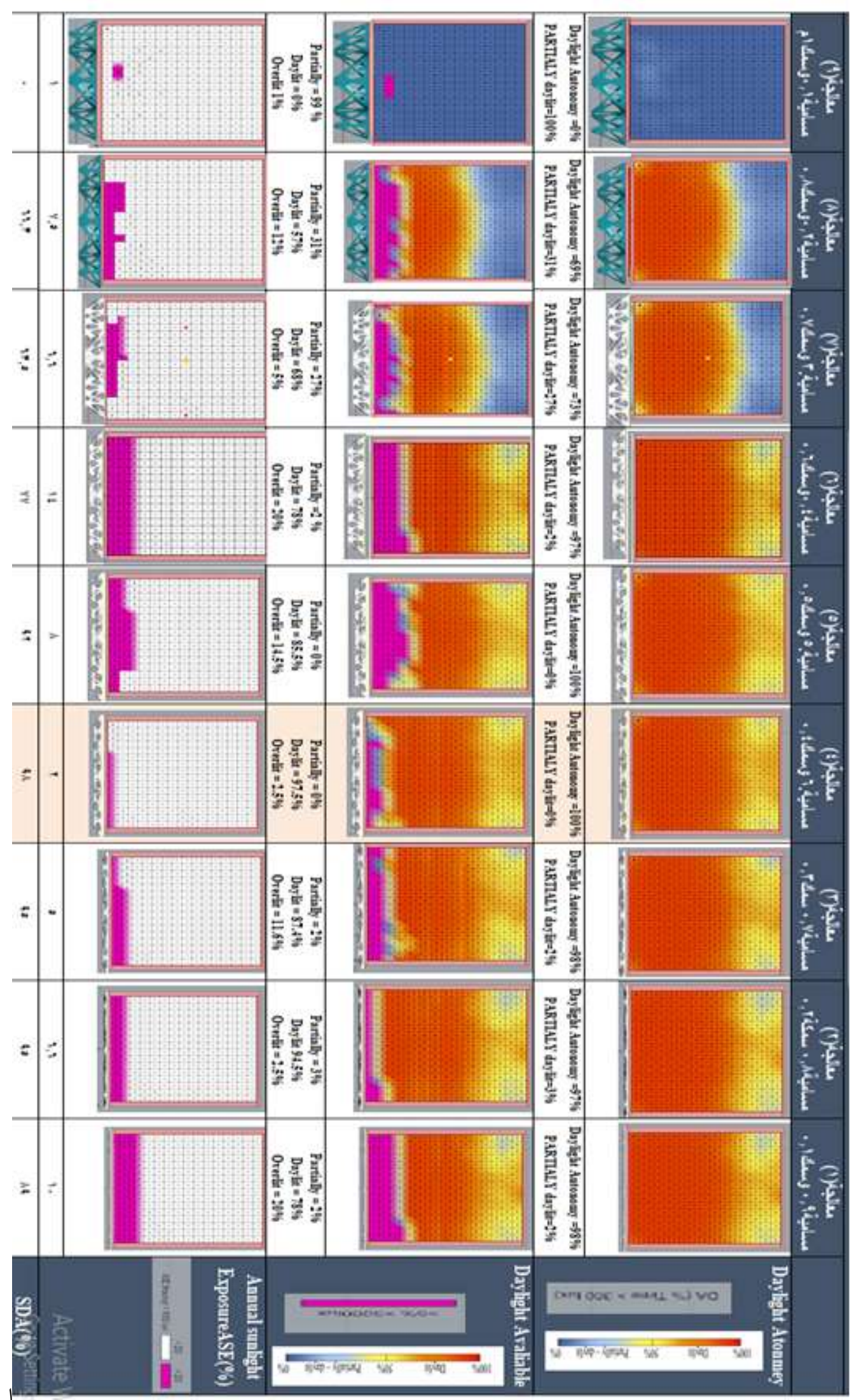

المصدر:الباحثة

من خلال نتائج المحاكاة السابقة تم رصد اهم نتائج تقييم الضوء الديناميكية وفقا لمعايير توضيحها سـابقا وكمـا هو 


\section{الواجهات المحاكية للطيعة وتثثيرها طلى أداء ضوء النهار والاداء الحرارى فى القراغ التعليمى}

$$
\text { موضح فى جدول التالى م جدول( · (1) يوضح نتائج للغلاف المحاكى لنبات الصبار وفقا معايير القياس الديناميكنة }
$$

\begin{tabular}{|c|c|c|c|c|c|c|}
\hline & \multirow{2}{*}{$\begin{array}{l}\text { Daylight } \\
\text { Atonmey }\end{array}$} & \multicolumn{3}{|c|}{ Daylight Avaliable } & \multirow{2}{*}{$\begin{array}{l}\text { Annual } \\
\text { sunlight } \\
\text { Exposure }\end{array}$} & \multirow[t]{2}{*}{$\operatorname{SDA}(\%)$} \\
\hline & & $\begin{array}{c}\text { PARTIALY } \\
\text { daylit }\end{array}$ & Daylit & Overlit & & \\
\hline معالجة (1) مسامية 9 , ، وسمك ا , • & $98 \%$ & $2 \%$ & $78 \%$ & $20 \%$ & 10 & 89 \\
\hline معالجة(Y)مساميةم, , وسمك Y , • & $97 \%$ & $3 \%$ & $94.5 \%$ & $2.5 \%$ & 6.6 & 95 \\
\hline معالجة(r)مسامية V , • وسمك ب, • & $98 \%$ & $2 \%$ & $87.4 \%$ & $11.6 \%$ & 5 & 95 \\
\hline معالجة(ع )مسامية 7 , وسمك \& , . & $100 \%$ & $0 \%$ & $97.5 \%$ & $2.5 \%$ & 2 & 98 \\
\hline معالجة(•)مساميةه , • وسمكه , • & $100 \%$ & $0 \%$ & $85.5 \%$ & $14.5 \%$ & 8 & 92 \\
\hline معالجة (7) مسامية ع , ، وسمك 7 , . & $97 \%$ & $2 \%$ & $78 \%$ & $20 \%$ & 14 & 77 \\
\hline معالجة(V)مسامية ب, ، وسمك V , • & $73 \%$ & $27 \%$ & $68 \%$ & $5 \%$ & 6.6 & 63.5 \\
\hline معالجة(^)مسامية ץ , • وسمكير , • & $69 \%$ & $31 \%$ & $57 \%$ & $12 \%$ & 7.5 & 66.3 \\
\hline معالجة(9)مسامية ا , ، وسمك| & $0 \%$ & $99 \%$ & 0 & $1 \%$ & 1 & 0 \\
\hline
\end{tabular}

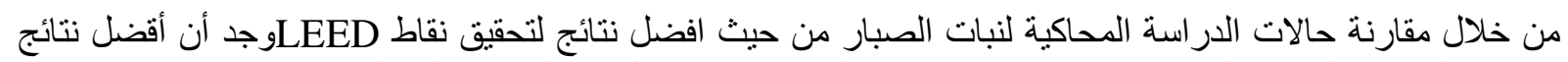

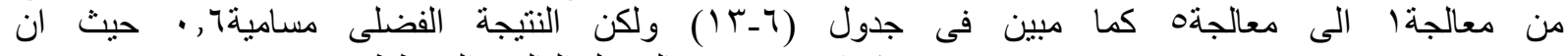
كما هو موضح بالجدول التالى و المخطط

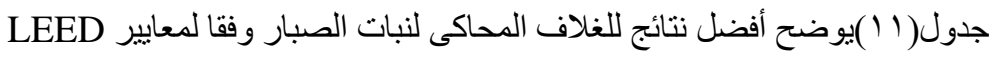
المصدر:الباحثة

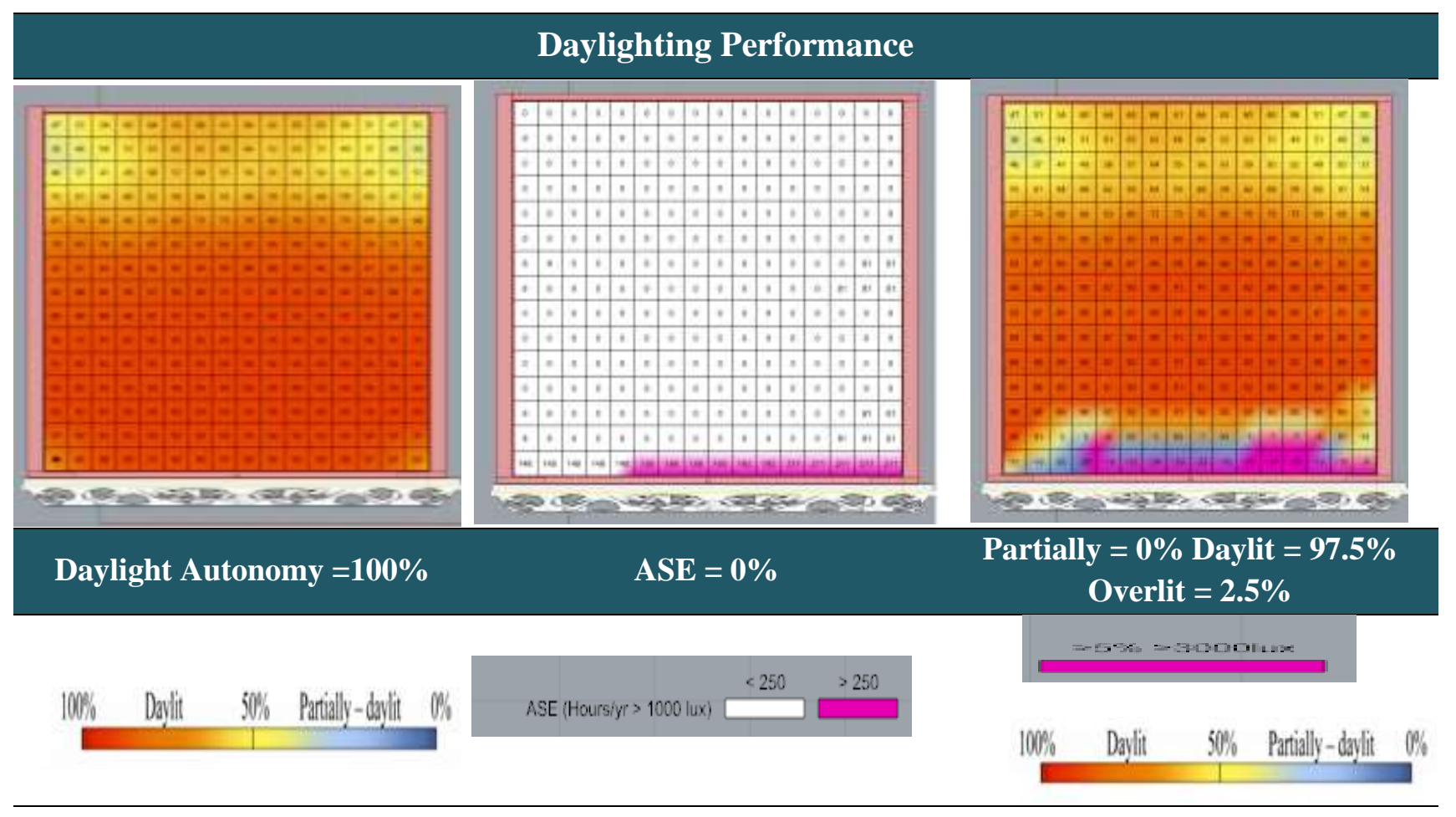




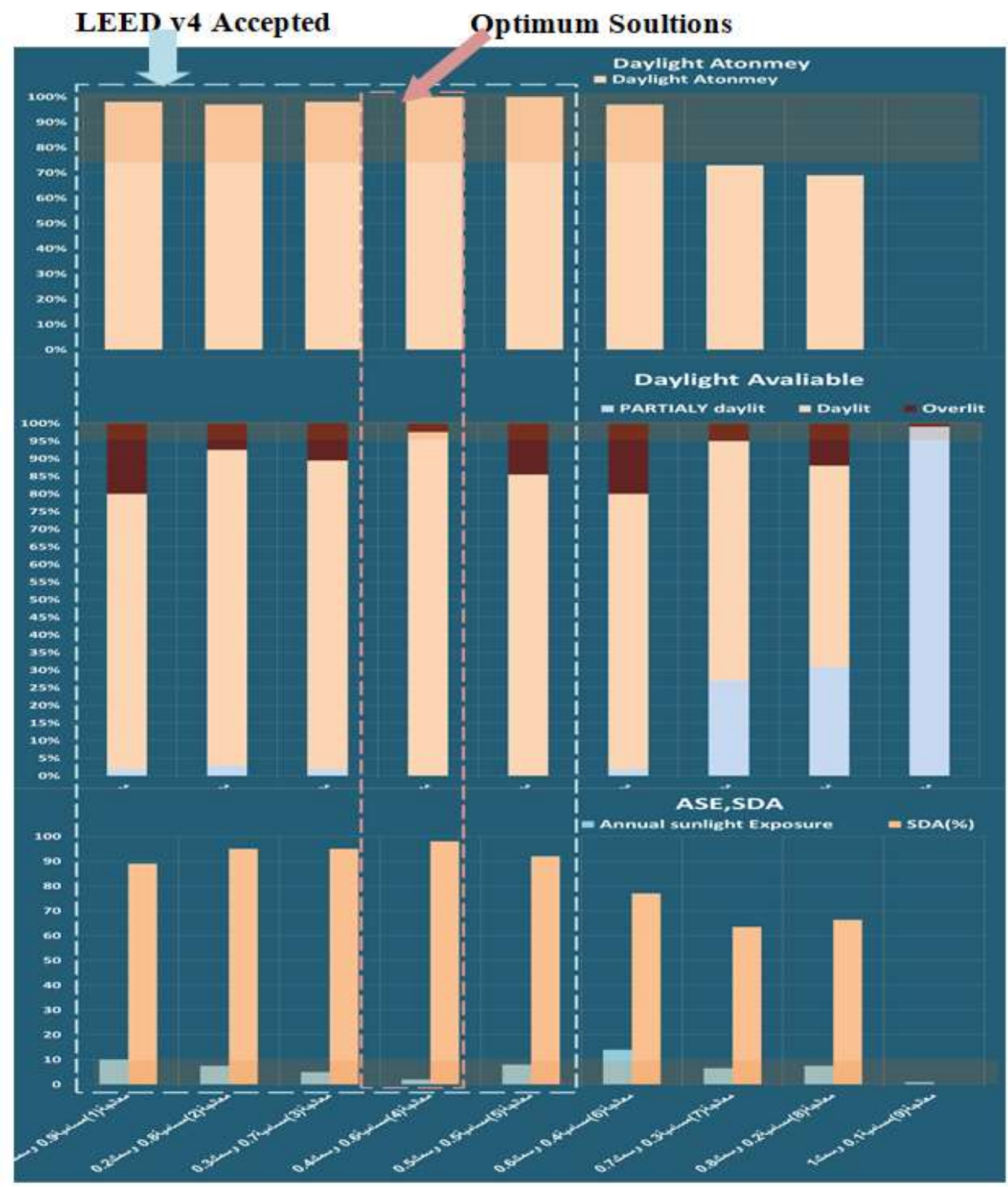

$$
\text { الثكل( () يوضح يوضح افضل نتائج للغلاف المحاكى لنبات الصبار وفقا معايير القياس الديناميكنة }
$$

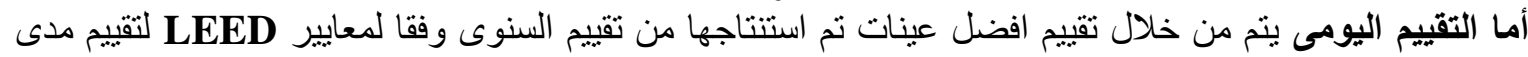

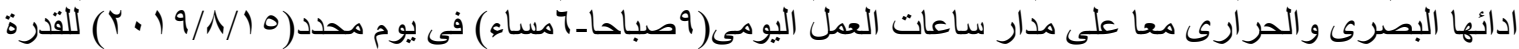

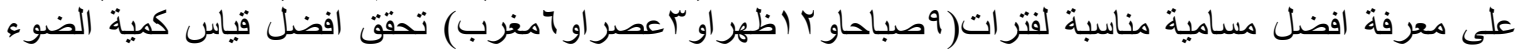
وتوزيعه خلال الفر اغ التعليمى المحدد مع تحقيق راحة حر ارية وفقا ASHREE55 كمن خلال مقارنة نتائج الحرارة

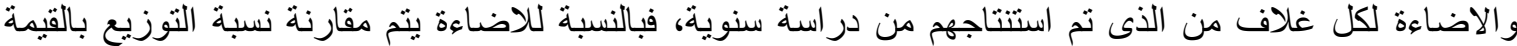

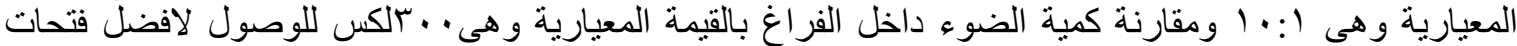
مناسبة مع الاوقات وهي المختلفة

\section{7.}

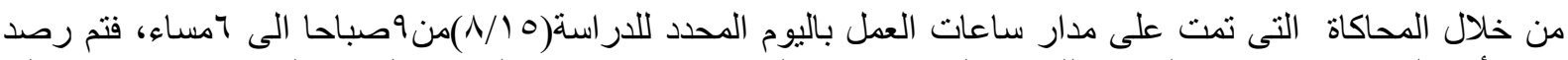

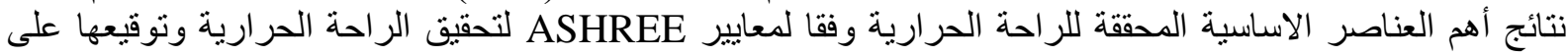
خريطة السيكومونرية لكل حالة ثم مقارنة افضل حالات للوصول الأنس لافضل حل يحقق راحة الحرارية، وتم رصد شدة

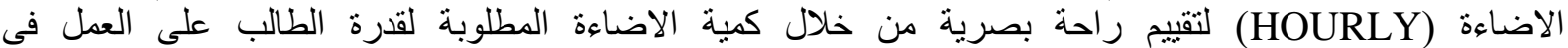

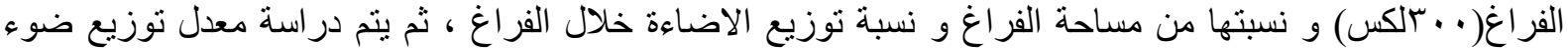




\section{الواجهات المحاكية للطييعة وتتثيرها على أداء ضوء النهار والاداء الحرارى فى الفراغ التطليمى}

النهار على مسافة ويتم رسم منحنى نوزيع الضوء لمقارنة النسبة الناتجة مع النسبة القياسية إ: • 1 لكل حالة دراسة تم

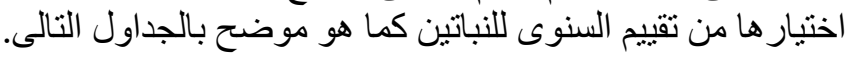
جدول(r ا (1) مقارنة بين تقييم اداء ضوء النهار اليومى و الحر ارى لافضل حالات نبات الصبار على ددار ساعات العمل

المصدر:الباحثة

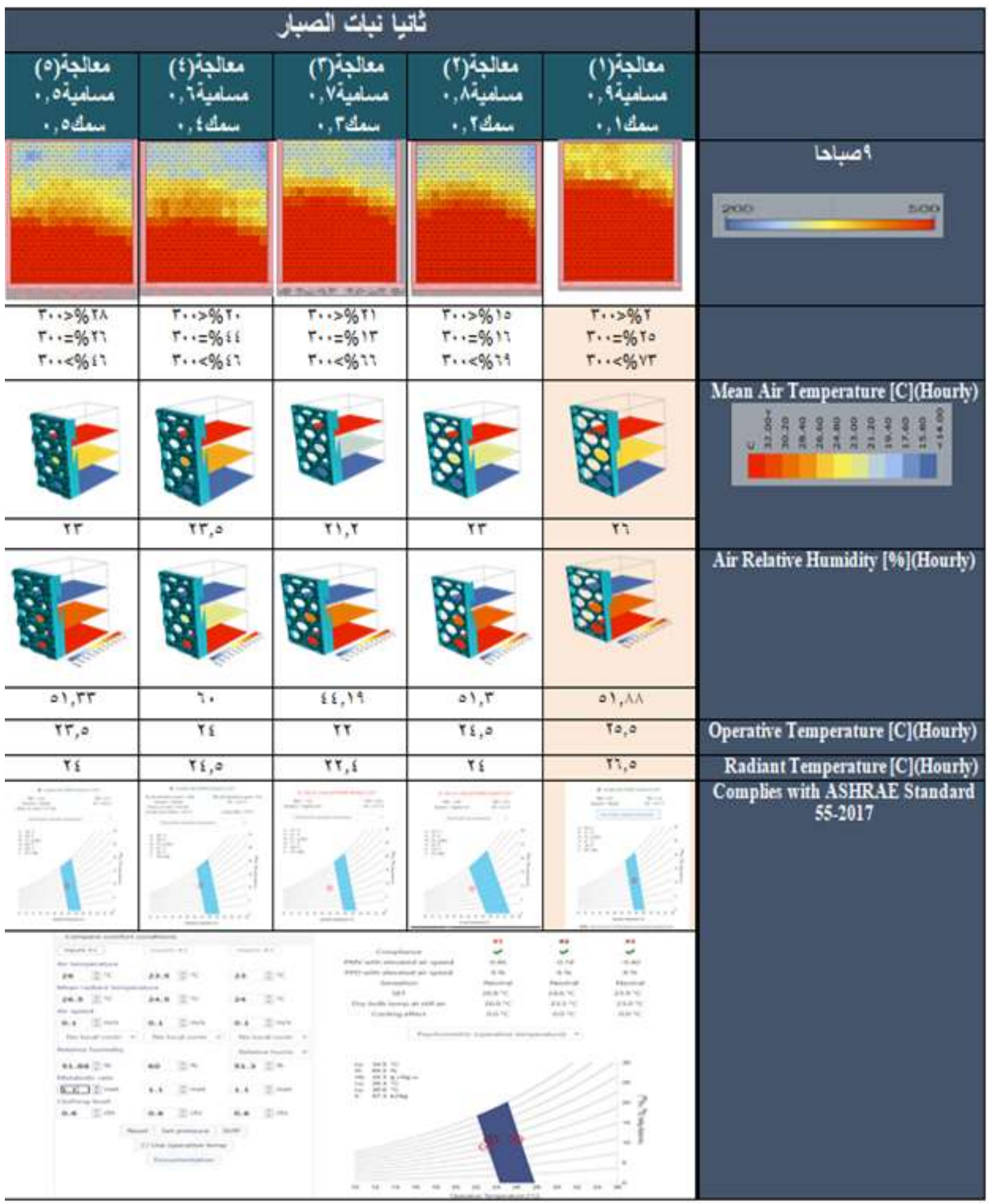


الواجهات المحاكية للطبيعة وتتثيرها طلى أداء ضوء النهار والاداء الحرارى فى الفراغ التطليمى

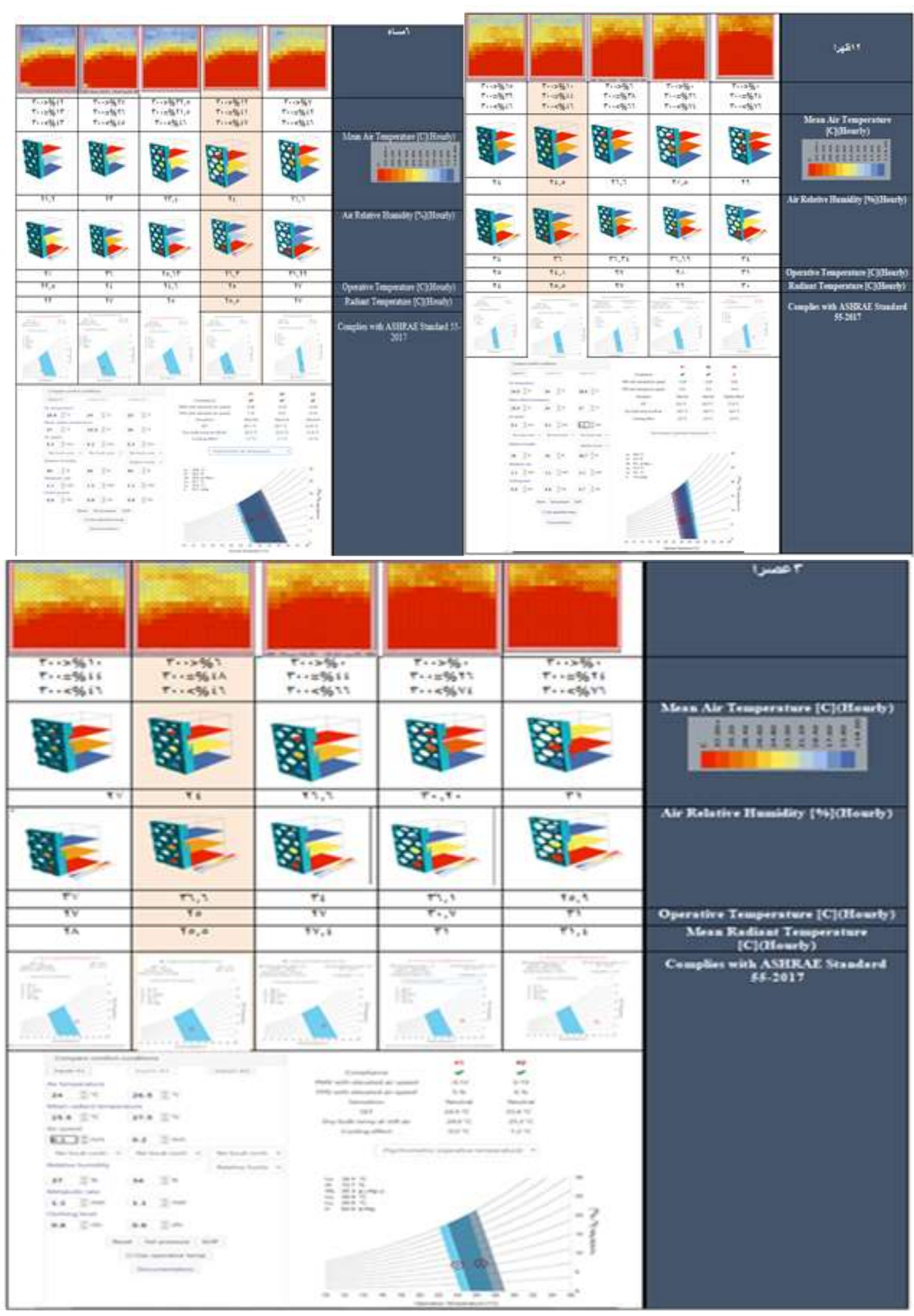


V. مناقشة نتائج تقييم الراحة البصرية والحرارية اليومية (لنبات الصبار-ثغرات النبات)

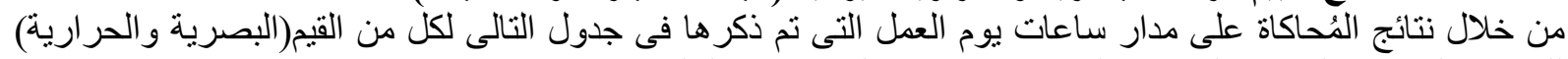

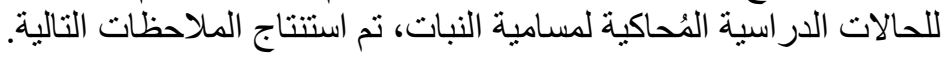

جدول(r ا1) متوسط ضوء النهار باللكس حالات نبات الصبار على مدار ساعات العمل

المصدر:الباحثة

\begin{tabular}{|c|c|c|c|c|c|c|c|c|c|c|c|c|c|c|c|c|}
\hline & \multicolumn{15}{|c|}{ الفالأن العائى البات الصبال } & \\
\hline & \multicolumn{15}{|c|}{ 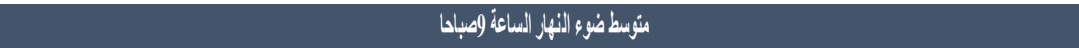 } & \\
\hline |list & 15 & 14 & 13 & 12 & 11 & 10 & 9 & 8 & 7 & 6 & 5 & 4 & 3 & 2 & 1 & \\
\hline تهُل العالجة & 1700 & 1550 & 1410 & 1290 & 1150 & 970 & 830 & 550 & 337 & 180 & 79 & 64 & 51 & 37 & 24 & 71 \\
\hline 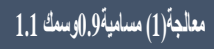 & 1650 & 1450 & 1343 & 1150 & 1000 & 850 & 750 & 570 & 500 & 363 & 345 & 338 & 300 & 295 & 250 & 7 \\
\hline 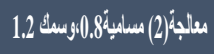 & 1550 & 1350 & 1260 & 1100 & 950 & 750 & 550 & 500 & 450 & 410 & 370 & 350 & 320 & 280 & 200 & 8 \\
\hline 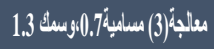 & 1460 & 1300 & 1200 & 1000 & 850 & 700 & 500 & 450 & 360 & 330 & 300 & 260 & 240 & 200 & 150 & 10 \\
\hline 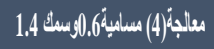 & 1350 & 1150 & 884 & 740 & 600 & 500 & 384 & 320 & 300 & 280 & 254 & 190 & 174 & 156 & 120 & 11 \\
\hline 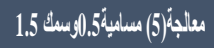 & 1200 & 1055 & 815 & 698 & 576 & 450 & 332 & 280 & 250 & 200 & 190 & 160 & 140 & 130 & 100 & 12 \\
\hline
\end{tabular}

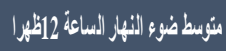

\begin{tabular}{|c|c|c|c|c|c|c|c|c|c|c|c|c|c|c|c|c|}
\hline الاعباi & 15 & 14 & 13 & 12 & 11 & 10 & 9 & 8 & 7 & 6 & 5 & 4 & 3 & 2 & 1 & \\
\hline قبل المقالجة & 1800 & 1650 & 1450 & 1300 & 1150 & 979 & 800 & 582 & 393 & 196 & 87 & 68 & 58 & 45 & 26 & 69 \\
\hline 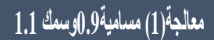 & 1772 & 1550 & 1450 & 1350 & 1200 & 1000 & 850 & 700 & 600 & 580 & 550 & 450 & 400 & 350 & 300 & 6 \\
\hline 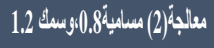 & 1700 & 1500 & 1350 & 1150 & 950 & 750 & 650 & 600 & 550 & 480 & 400 & 350 & 300 & 278 & 250 & 7 \\
\hline 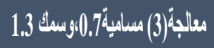 & 1650 & 1400 & 1250 & 1000 & 850 & 650 & 600 & 550 & 500 & 450 & 420 & 380 & 350 & 289 & 200 & 8 \\
\hline 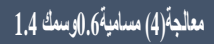 & 1600 & 1350 & 1200 & 950 & 750 & 600 & 550 & 500 & 440 & 400 & 350 & 328 & 300 & 250 & 170 & 9 \\
\hline 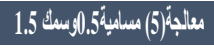 & 1500 & 1300 & 1150 & 850 & 650 & 550 & 500 & 450 & 400 & 350 & 300 & 270 & 250 & 200 & 150 & 10 \\
\hline & & & & & & & | $\Delta \leq 3$ & d) 4 & توبطة & & & & & & & \\
\hline
\end{tabular}

iws

\begin{tabular}{|l|l|l|l|l|l|l|l|l|l|l|l|l|l|l|}
15 & 14 & 13 & 12 & 11 & 10 & 9 & 8 & 7 & 6 & 5 & 4 & 3 & 2 & 1
\end{tabular}

\begin{tabular}{|c|c|c|c|c|c|c|c|c|c|c|c|c|c|c|c|c|}
\hline ثلب العالجة & 1862 & 1742 & 1650 & 1500 & 1280 & 1096 & 900 & 750 & 425 & 215 & 92 & 79 & 62 & 49 & 32 & 58 \\
\hline 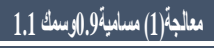 & 1800 & 1600 & 1500 & 1350 & 1200 & 1000 & 850 & 700 & 600 & 580 & 550 & 500 & 450 & 400 & 360 & 5 \\
\hline 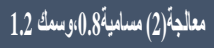 & 1750 & 1550 & 1350 & 1040 & 880 & 790 & 700 & 600 & 550 & 500 & 500 & 485 & 425 & 365 & 350 & 5 \\
\hline 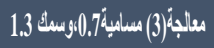 & 1700 & 1400 & 1250 & 980 & 840 & 786 & 661 & 584 & 500 & 463 & 431 & 428 & 400 & 310 & 250 & 7 \\
\hline 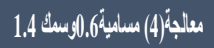 & 1650 & 1390 & 1200 & 960 & 800 & 700 & 550 & 500 & 450 & 429 & 412 & 380 & 350 & 289 & 200 & 8 \\
\hline 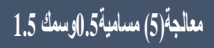 & 1600 & 1345 & 1164 & 900 & 750 & 650 & 520 & 463 & 431 & 415 & 378 & 353 & 320 & 276 & 170 & 9 \\
\hline & \multicolumn{15}{|c|}{ 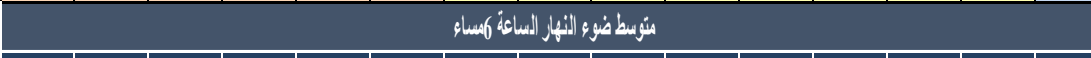 } & \\
\hline الاعثأi & 15 & 14 & 13 & 12 & 11 & 10 & 9 & 8 & 7 & 6 & 5 & 4 & 3 & 2 & 1 & \\
\hline تَّل المعلدة. & 1550 & 1350 & 1200 & 1000 & 900 & 800 & 650 & 500 & 340 & 165 & 76 & 64 & 47 & 33 & 20 & 78 \\
\hline 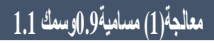 & 1445 & 1300 & 1150 & 950 & 850 & 740 & 500 & 440 & 400 & 350 & 300 & 255 & 200 & 170 & 128 & 11 \\
\hline 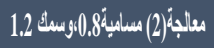 & 1336 & 1144 & 1000 & 850 & 750 & 550 & 400 & 320 & 300 & 280 & 254 & 184 & 174 & 156 & 128 & 10 \\
\hline 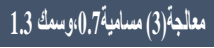 & 1280 & 1100 & 950 & 750 & 600 & 452 & 320 & 300 & 260 & 200 & 200 & 168 & 148 & 136 & 90 & 14 \\
\hline 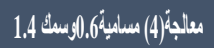 & 1240 & 1050 & 800 & 700 & 550 & 450 & 350 & 280 & 228 & 176 & 160 & 152 & 148 & 132 & 86 & 14 \\
\hline 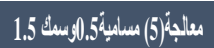 & 1100 & 950 & 750 & 650 & 500 & 320 & 264 & 204 & 168 & 144 & 120 & 112 & 104 & 96 & 60 & 18 \\
\hline
\end{tabular}


أولالالساعة التاسعة صباحا

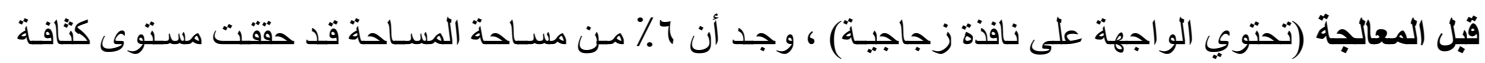

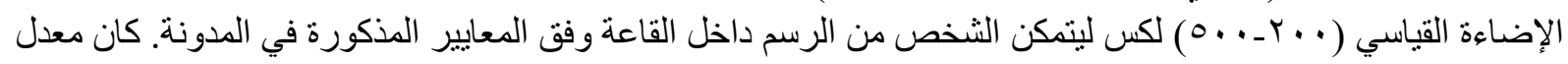

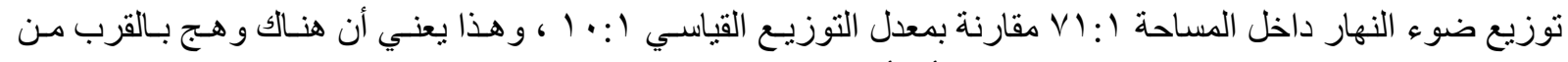

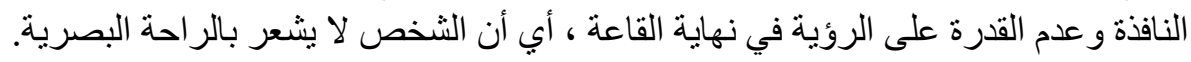

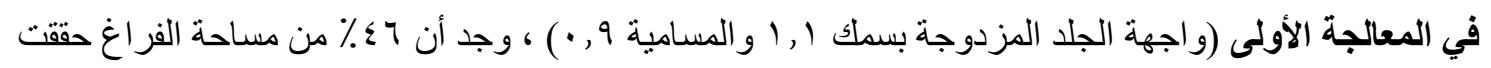

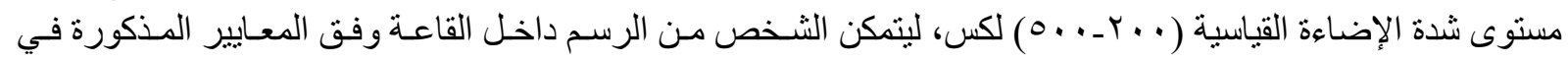

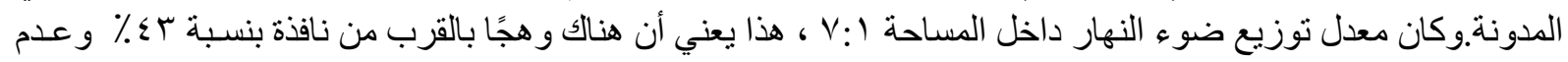

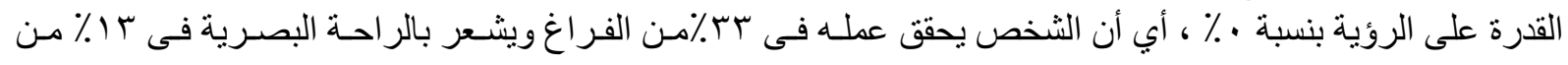
الفراغ.

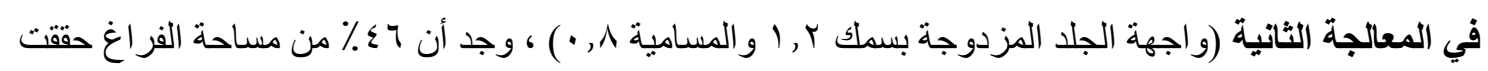

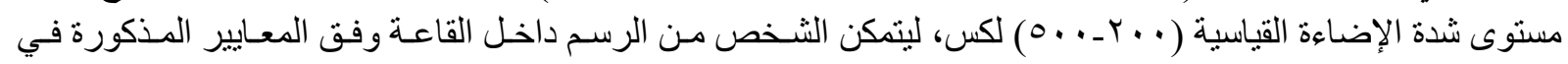

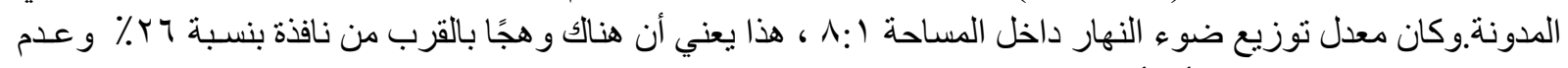

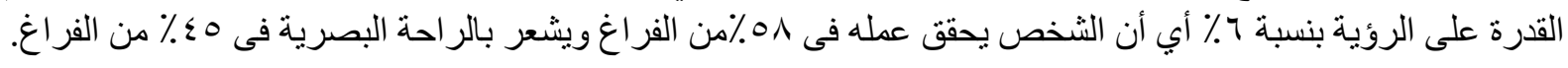

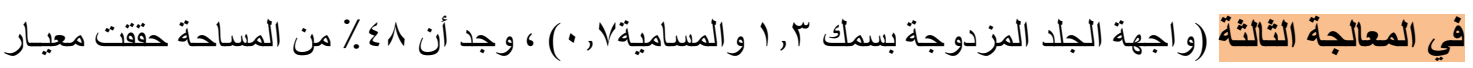

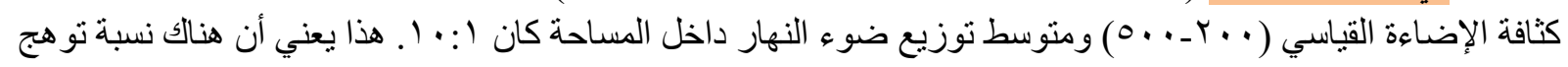

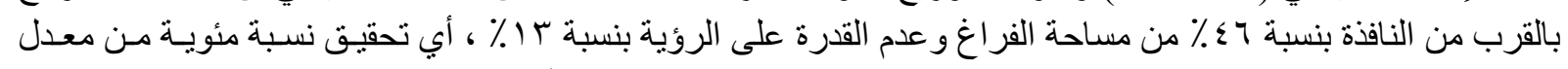

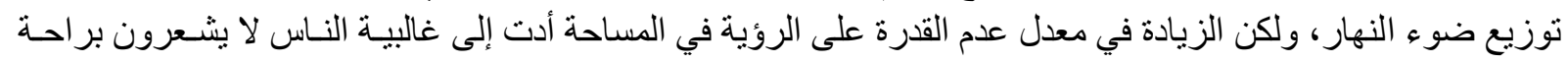
بصرية داخل الفراغ.

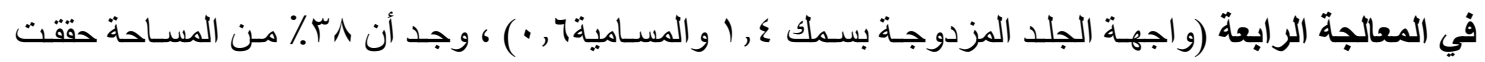

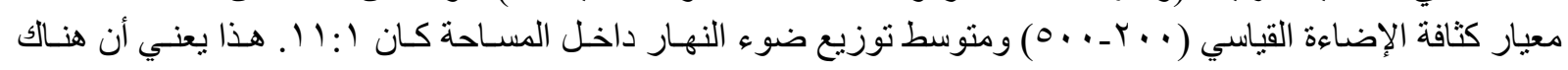

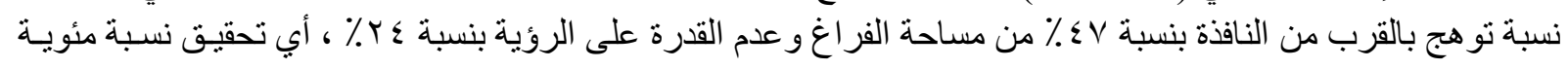

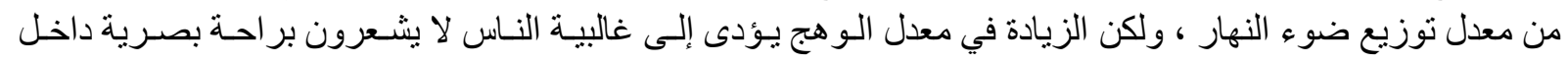
الفراغ.

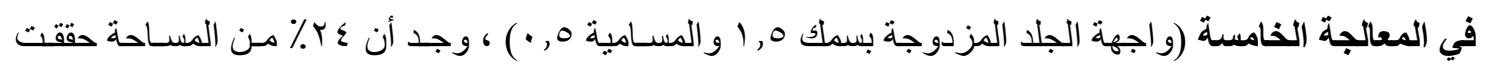

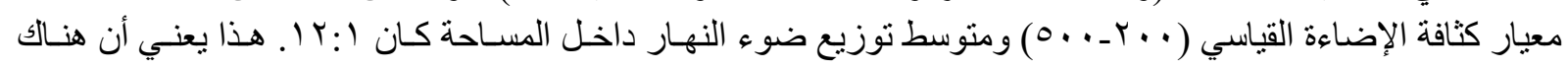

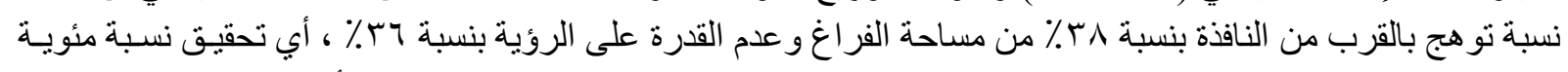

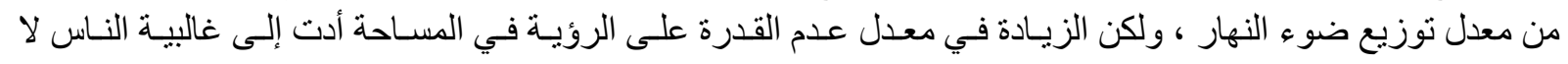
يشعرون بر احة بصرية داخل الفراغ. 


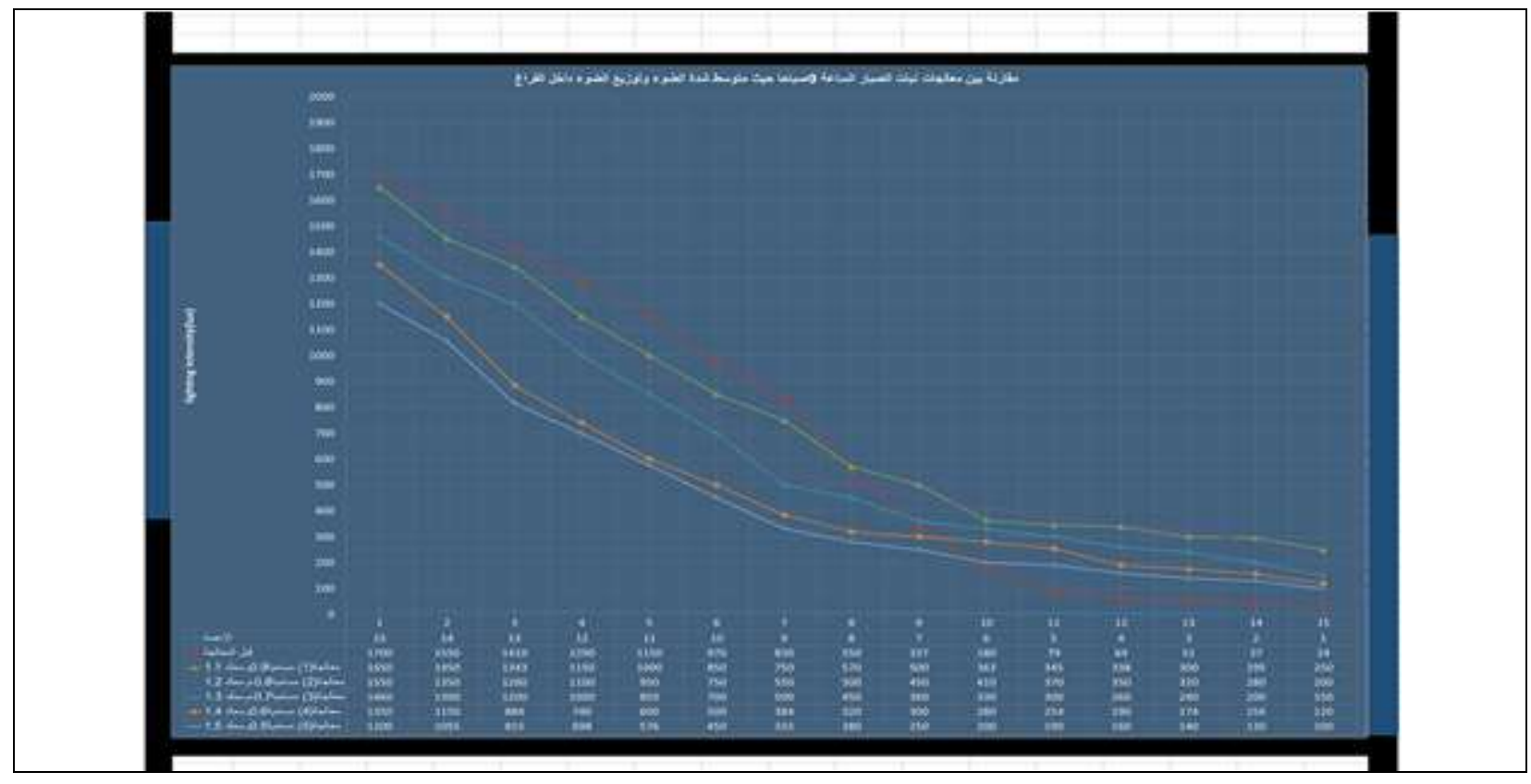

شكل(V) يوضح مقارنة بين معالجات نبات الصبار الساعةوصباحا من حيث (متوسط مستوى الإضلاءة وتوزيعها) المصدر : الباحثة

ثانيا الساعة الثانية عشر ظهرا

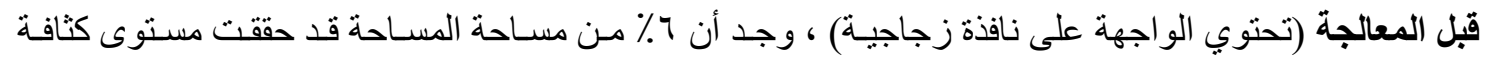

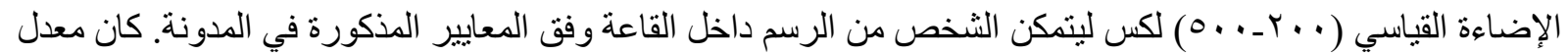

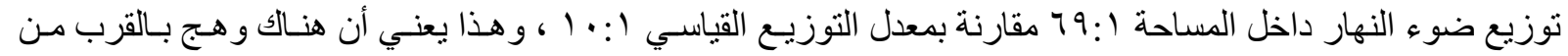

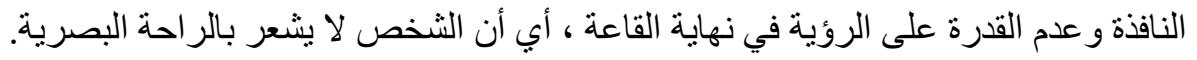

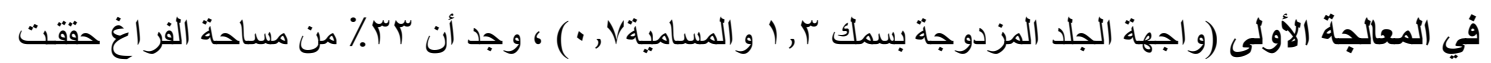

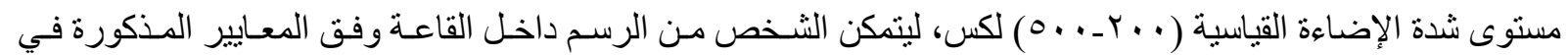

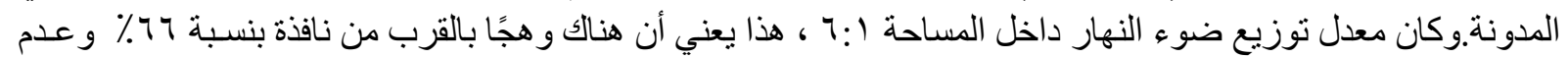

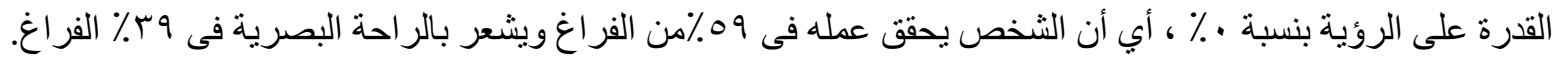

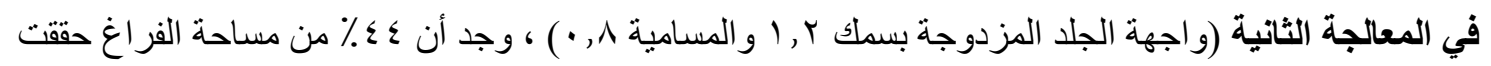

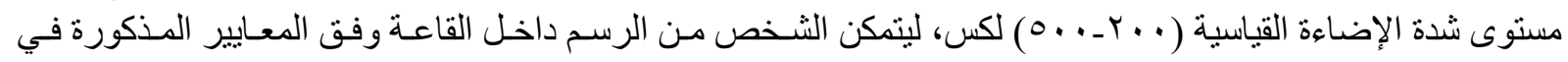

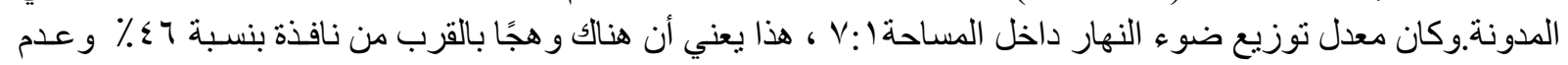

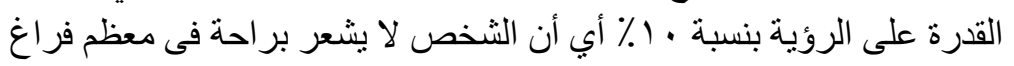

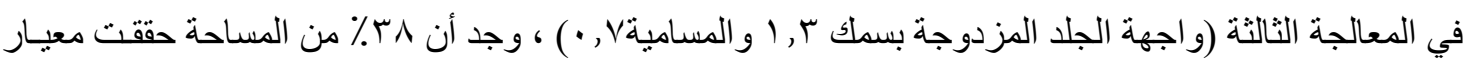

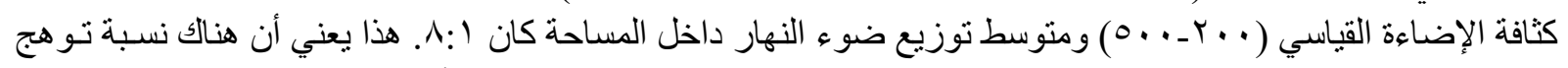

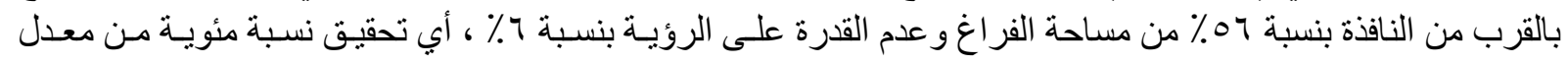

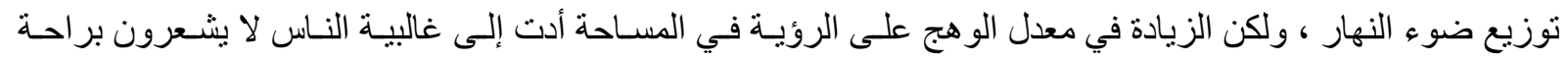
بصرية داخل الفراغ.

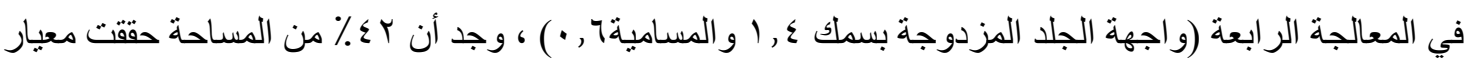

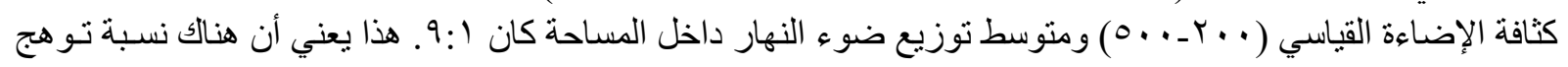

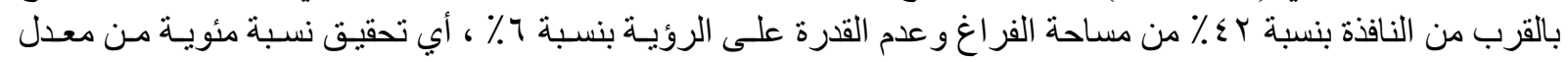

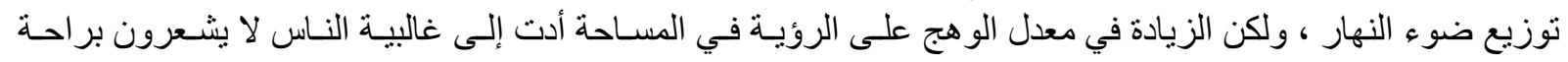
بصرية داخل الفراغ. 


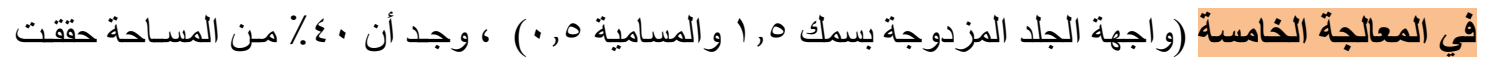

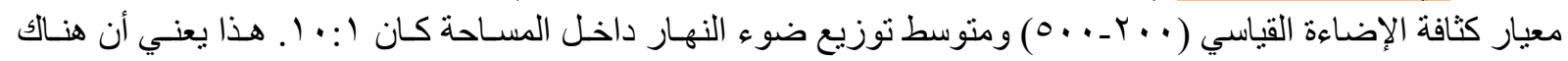

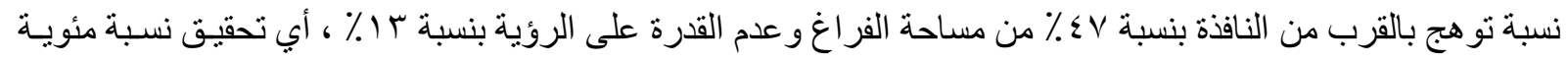

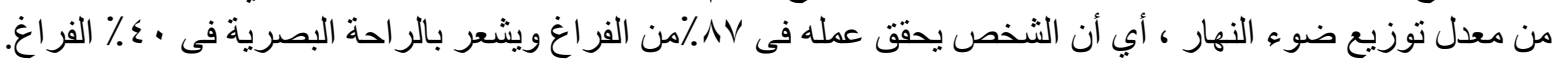

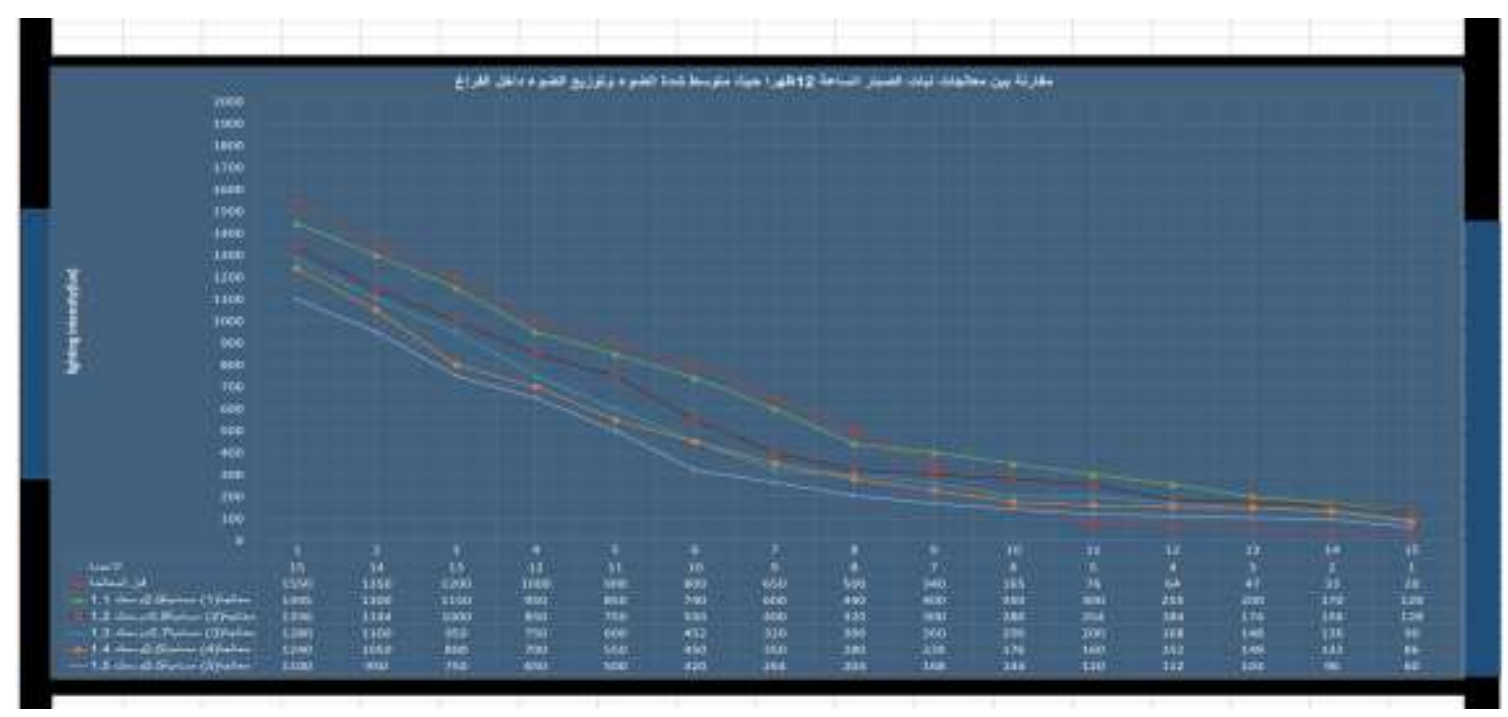

شكل(^) يوضح مقارنة بين معالجات نبات الصبار الساعة ب اظهر ا من حيث (متوسط مستوى الإضاءة وتوزيعها)

ثالثا الساعة الثالثة عصرا

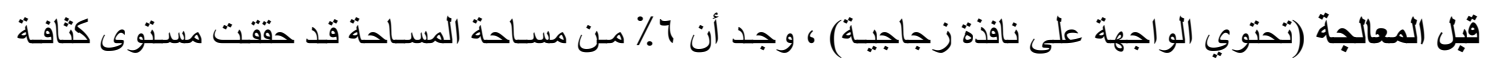

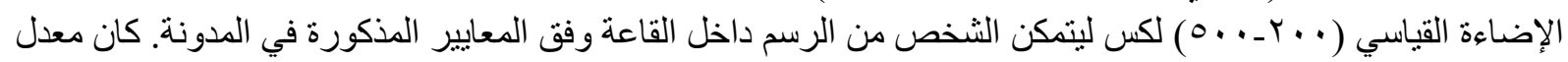

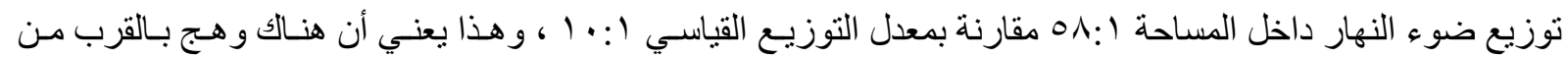

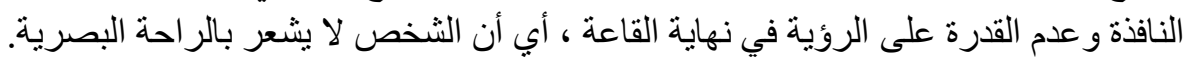

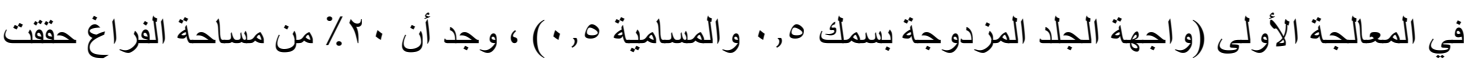

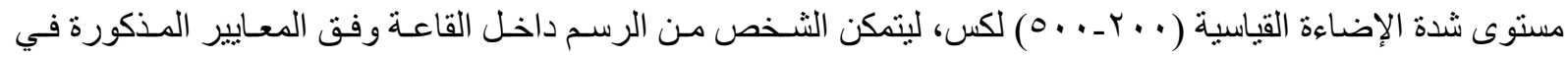

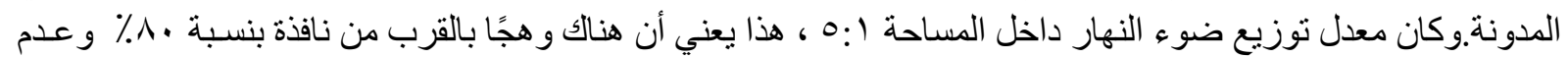

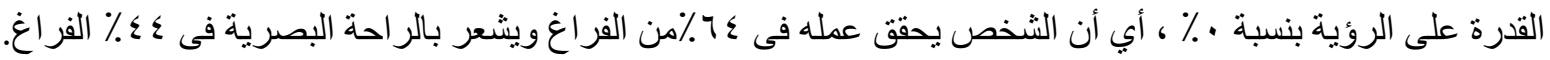

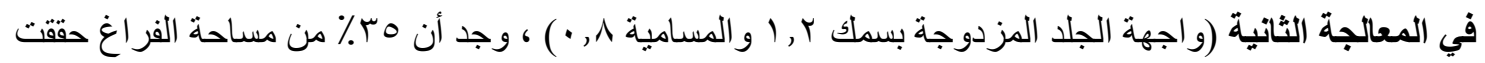

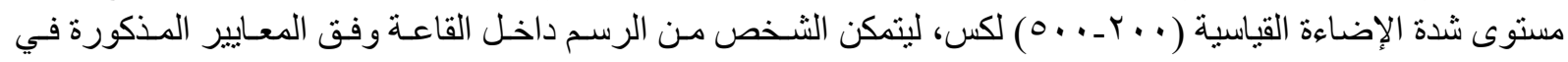

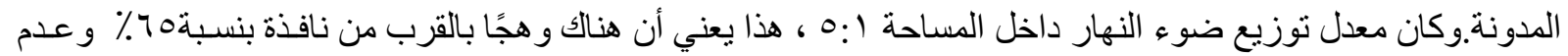

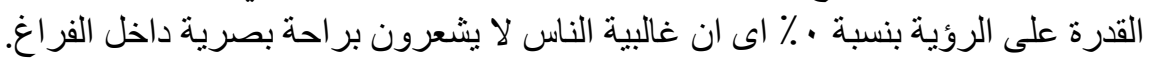

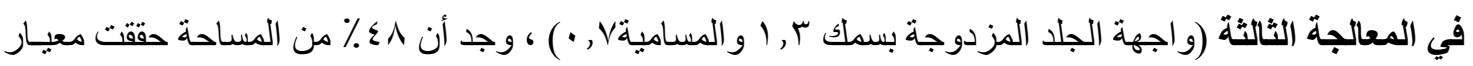

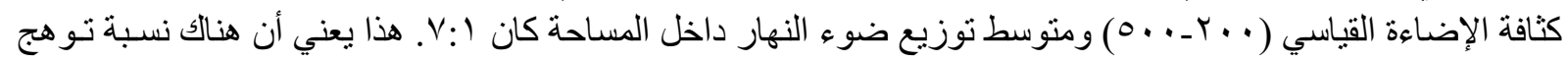

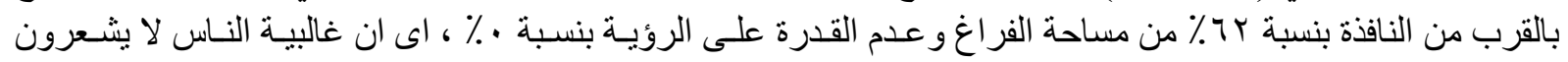
بر احة بصرية داخل الفراغ.

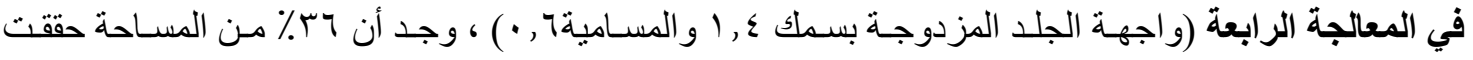

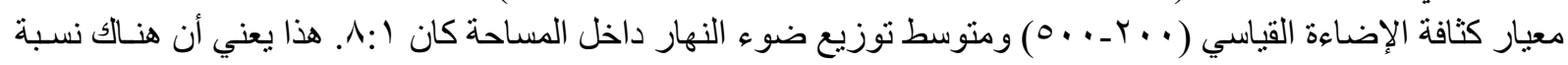

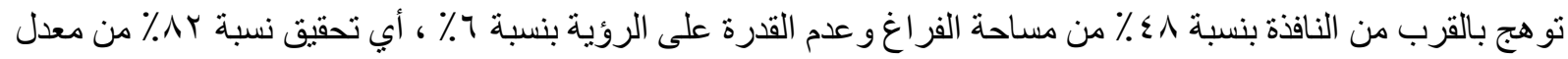

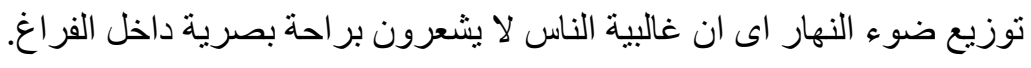




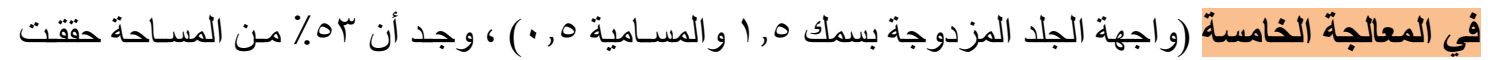

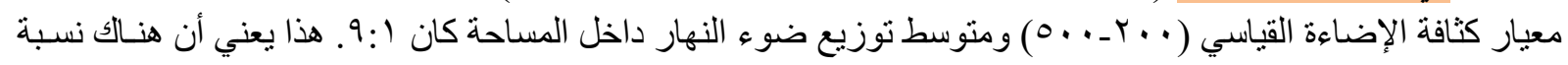

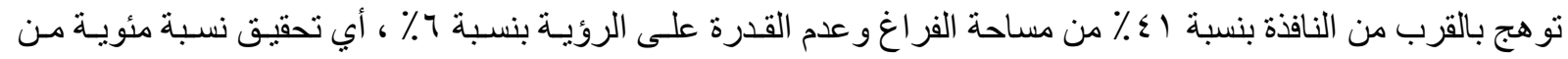

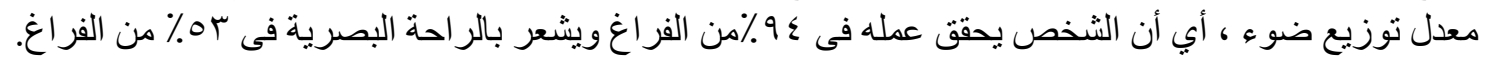

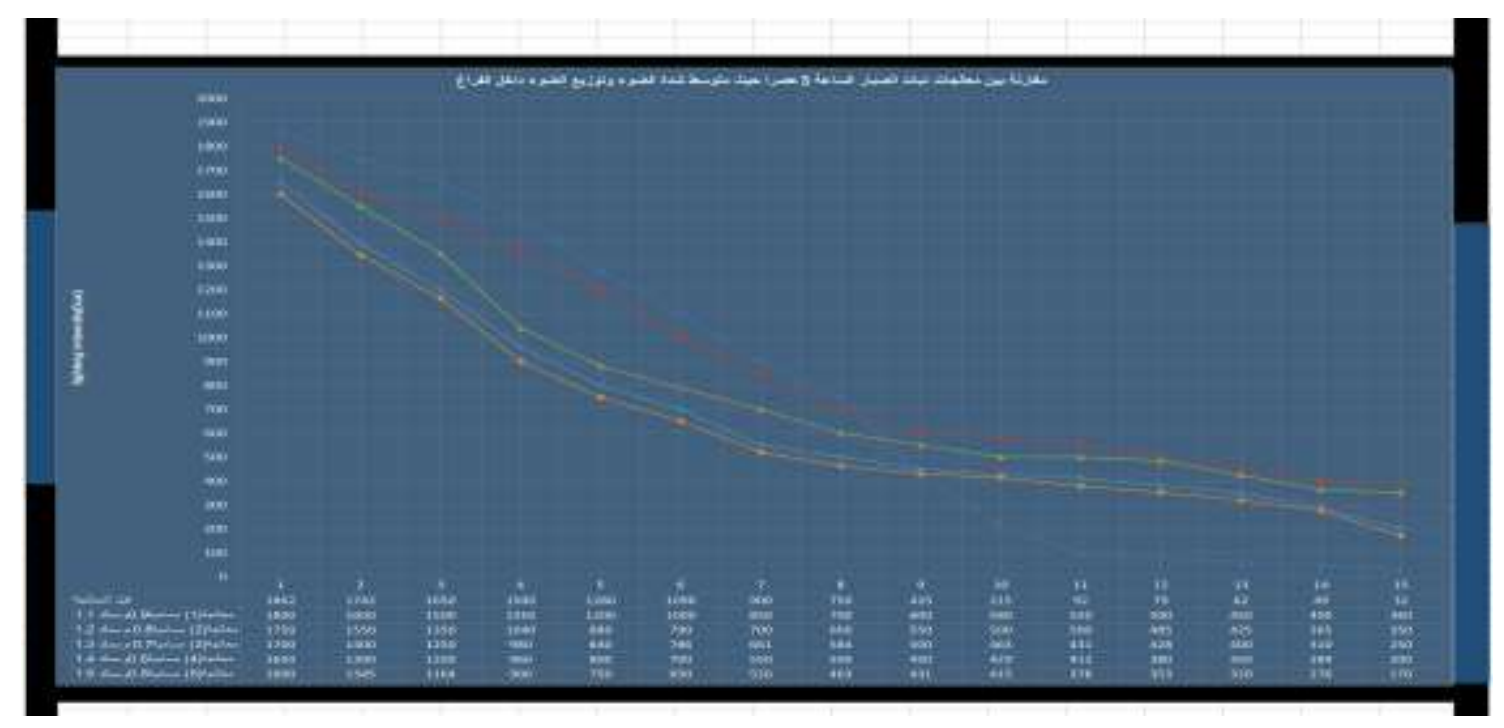

شكل(9) مقارنة بين معالجات نبات الصبار الساعة اعصر ا من حيث (متوسط مستوى الإضاءة وتوزيعها) المصدر : الباحثة

ثالثا الساعة السادسة

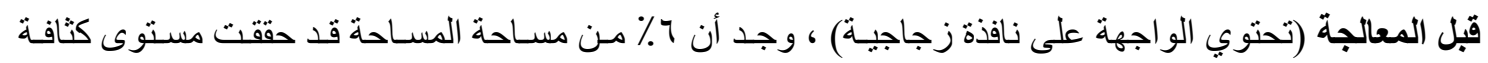

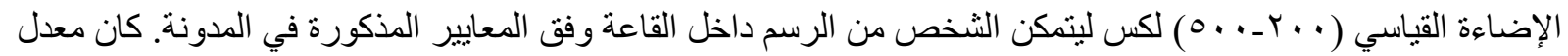

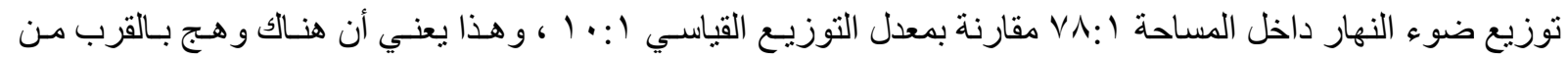

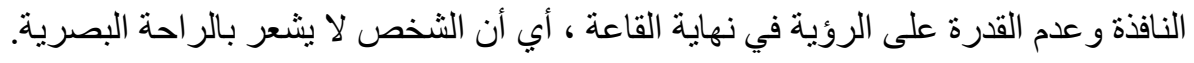

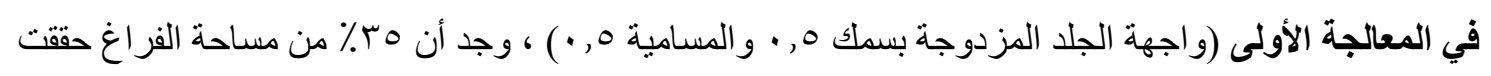

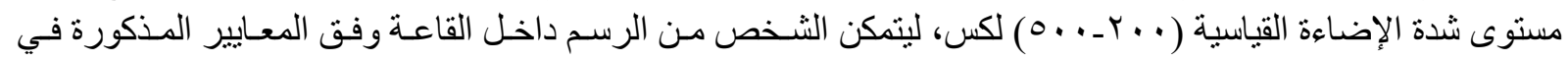

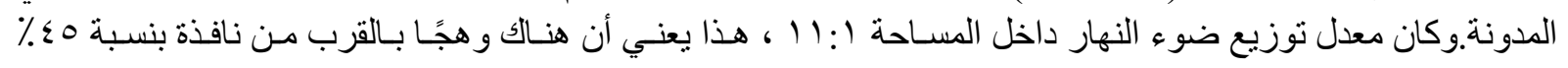

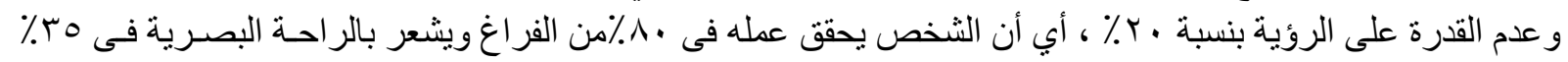
الفراغ.

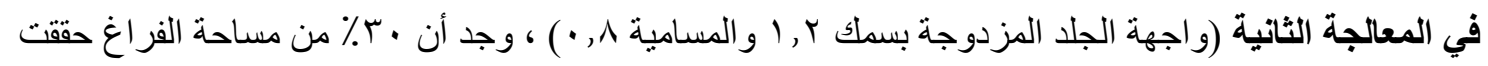

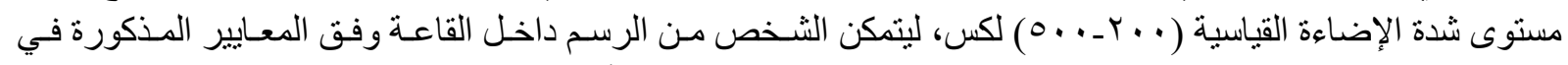

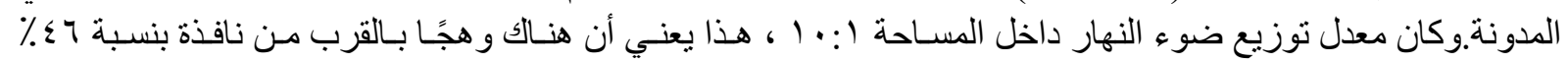

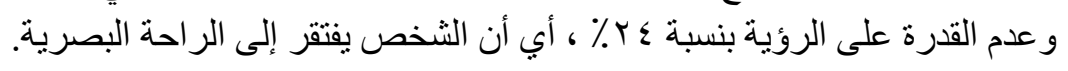

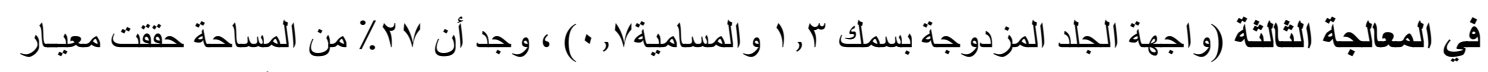

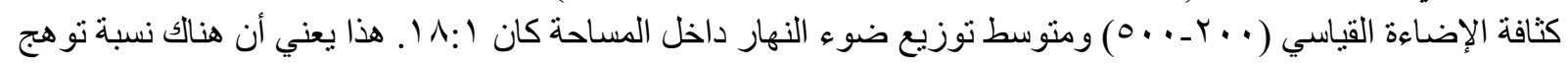

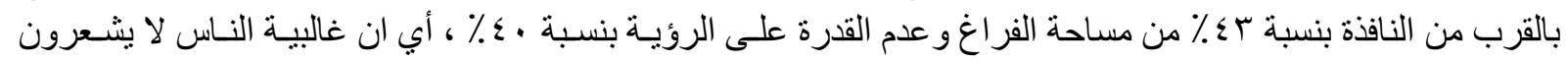

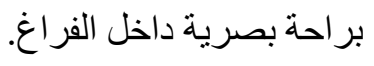

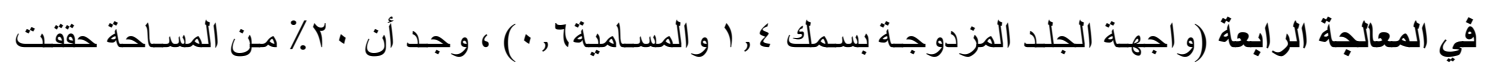

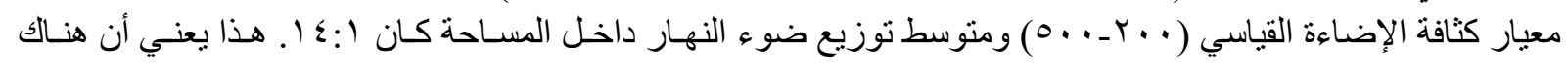




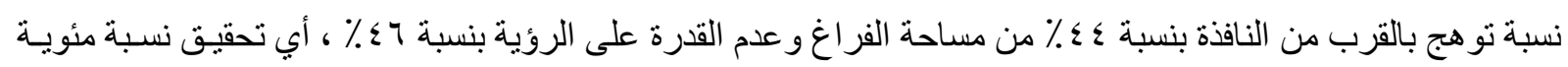

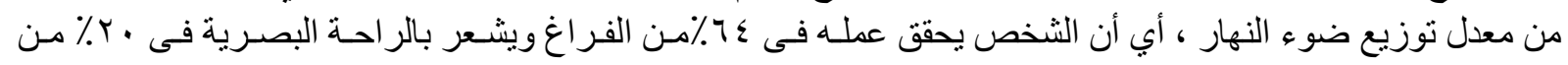
الفراغ.

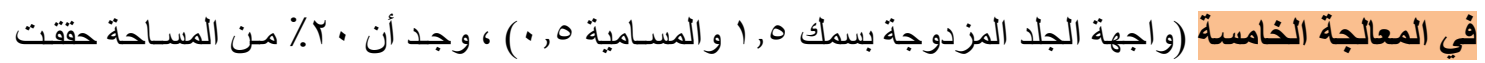

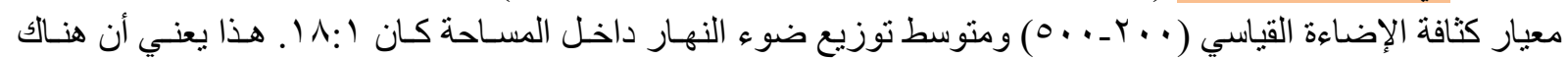

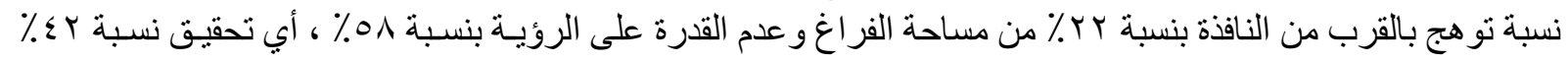

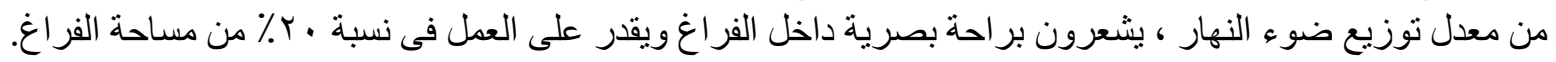

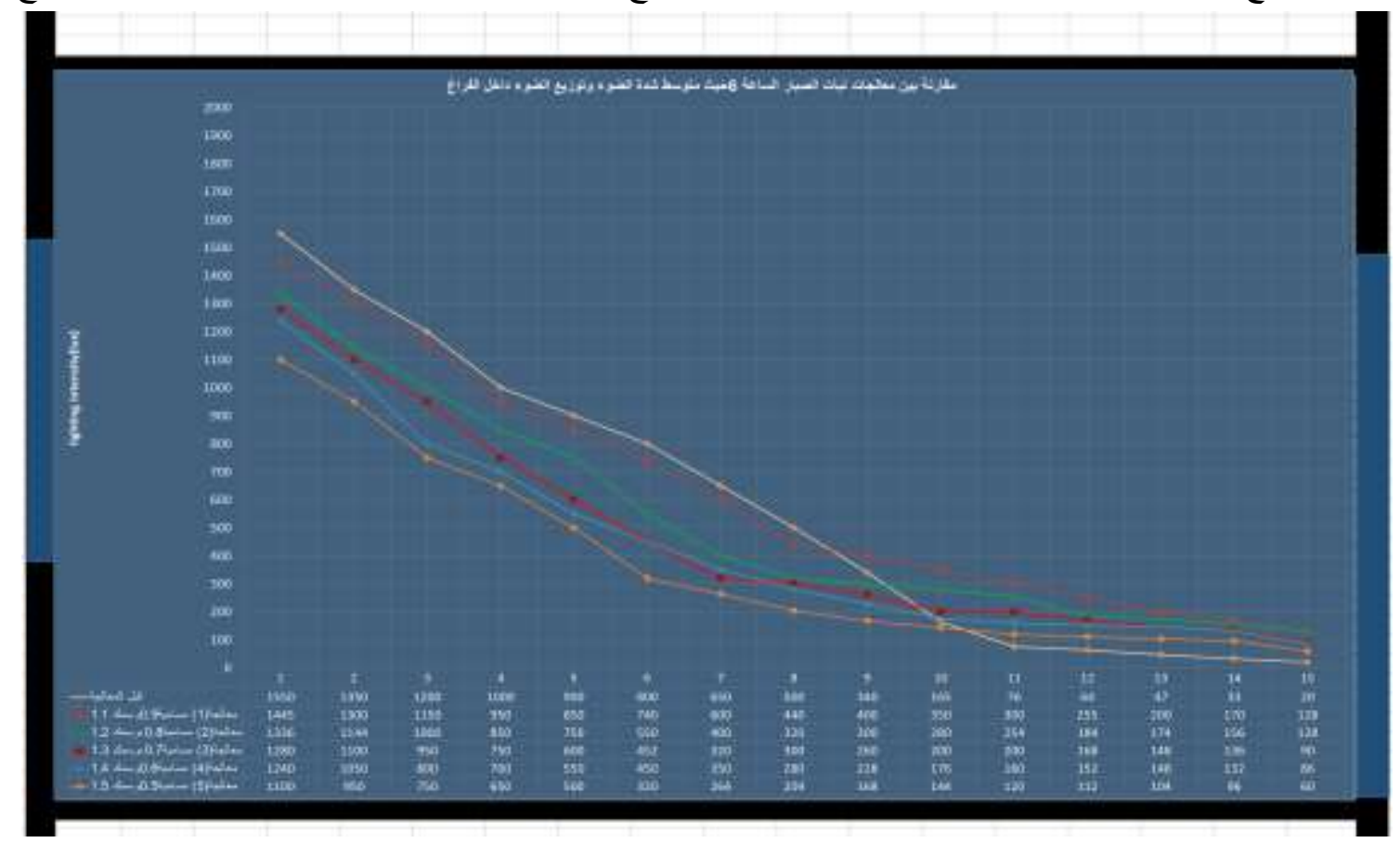

شكل( • () مقارنة بين معالجات نبات الصبار الساعة آمساء من حيث (منوسط مستوى الإضاءة ونوزيعها)

$$
\text { المصدر : الباحثة }
$$

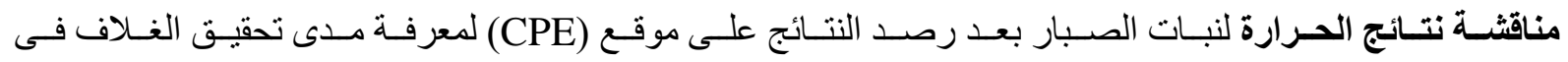

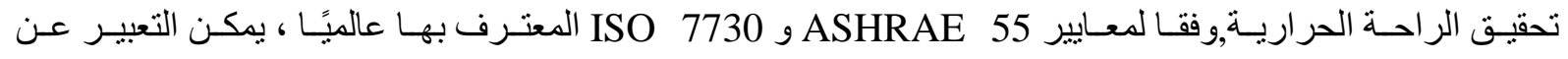

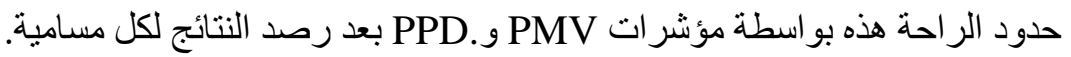

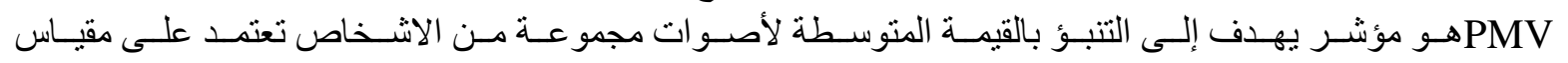

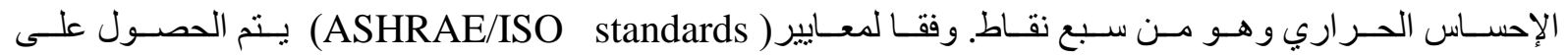

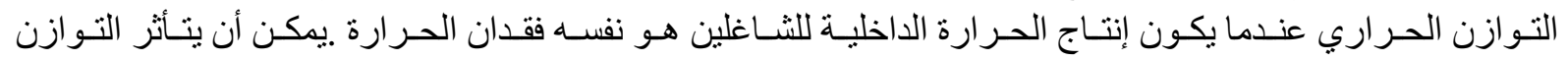

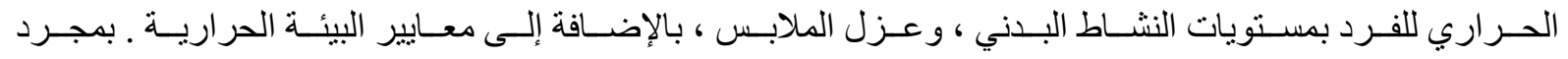

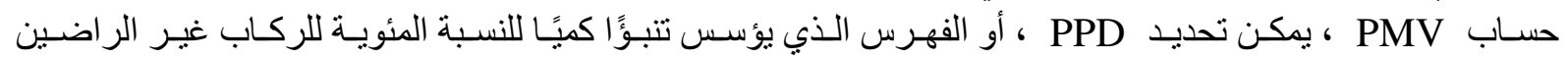

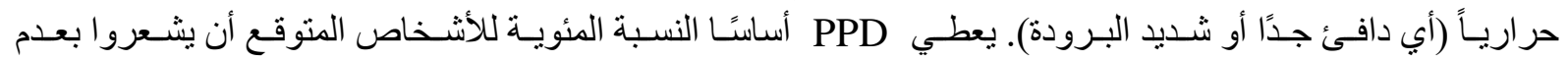

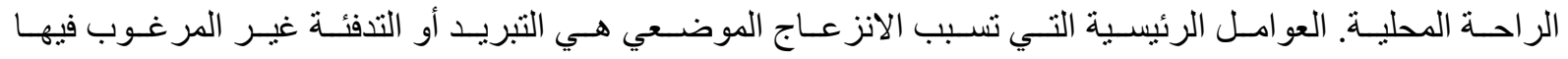

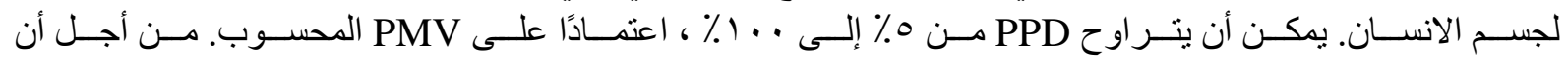

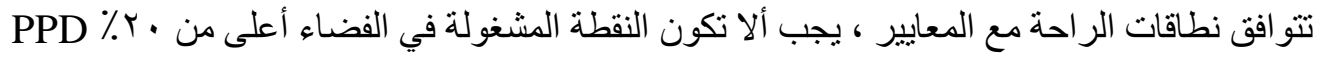

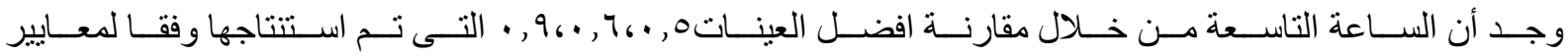
Sما موضح بالمخطط التالى وجد ان مسامية 7 , • افضل مسامية. 

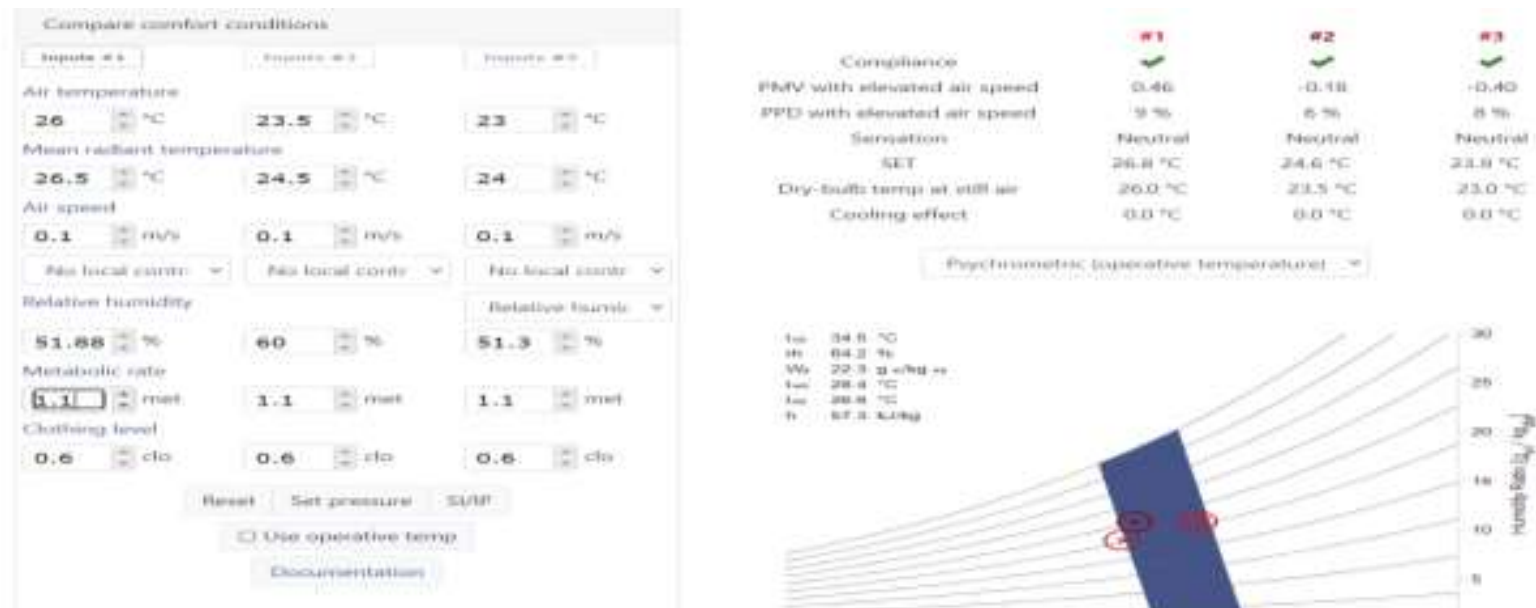

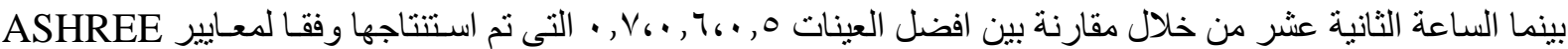
كما موضح بالمخطط التالى وجد ان مسامية ب ب ر • افضل مسامية.
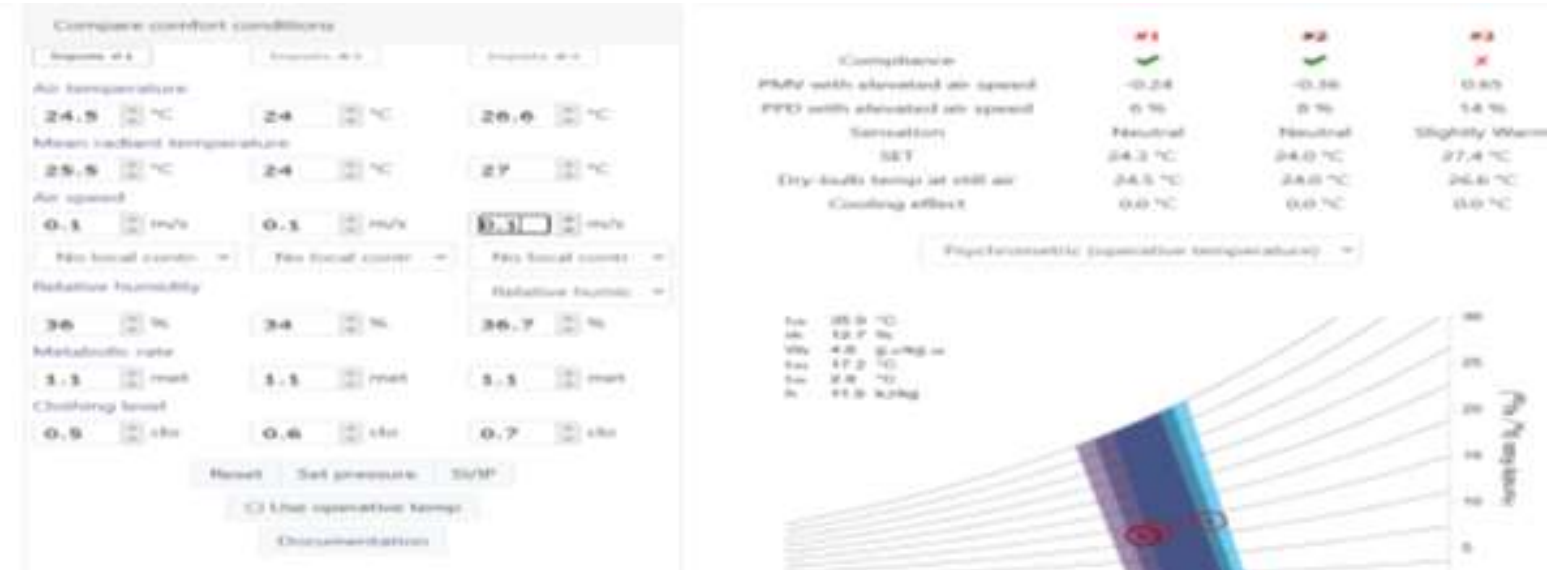

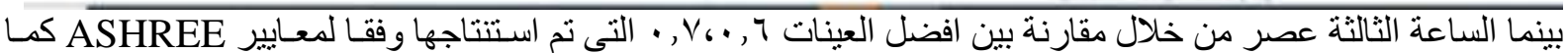
موضح بالمخطط التالى وجد ان مسامية 7, ، افضل مسامية.
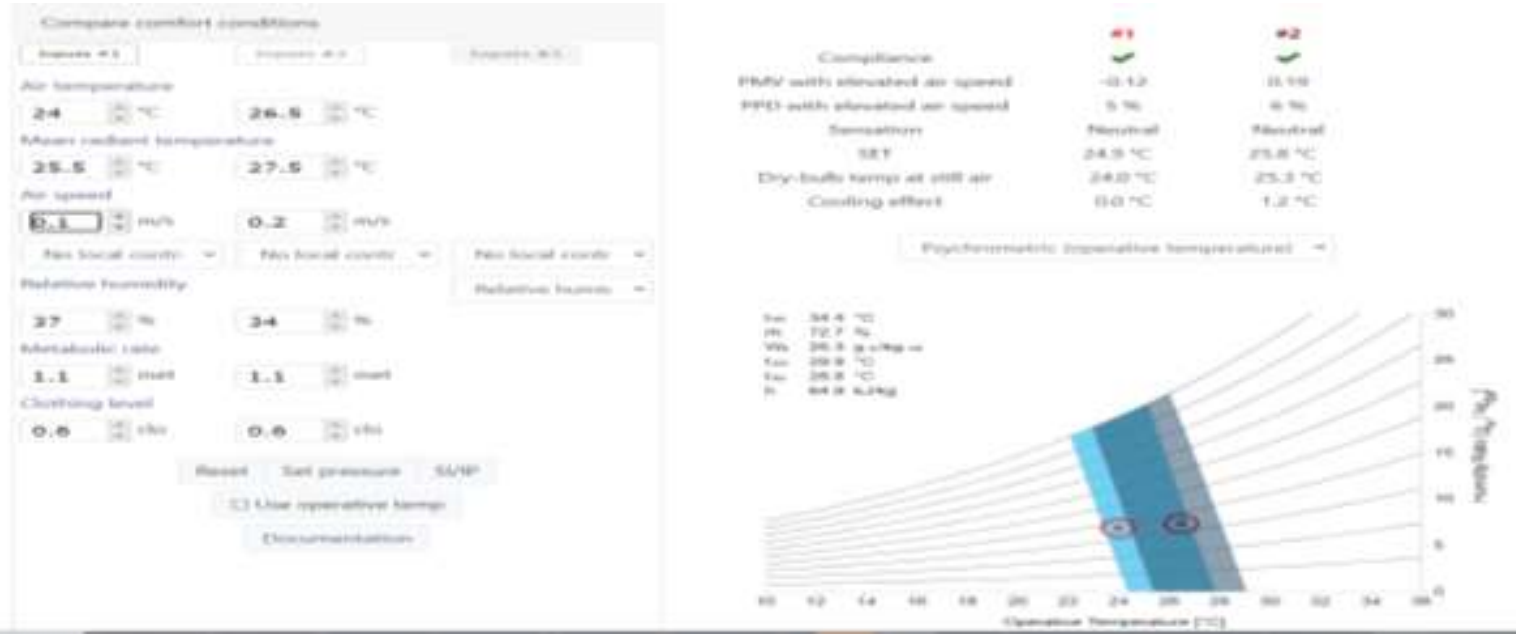


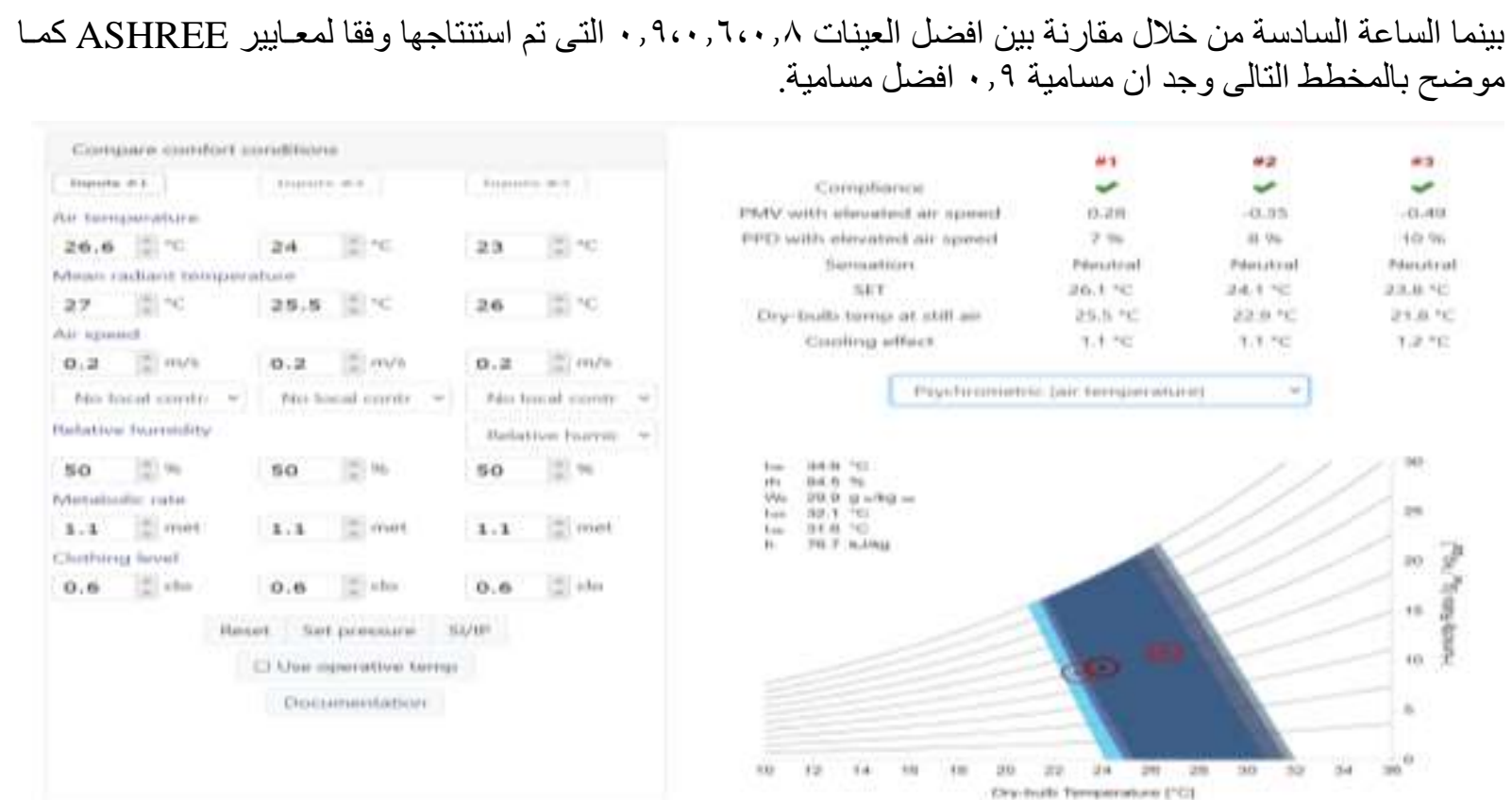

وفقًا للنتائج المذكورة أعلاه ،وجد ان من خلال تطابق ومناقثة عينات نبات الصبار وجد الساعةهواصباحا حالة

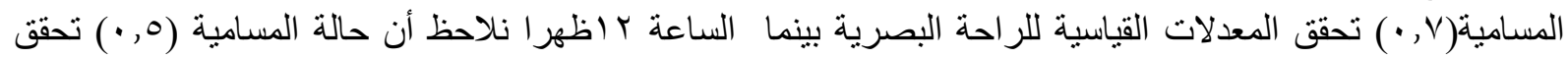

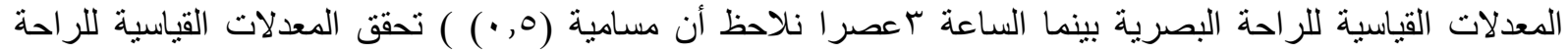

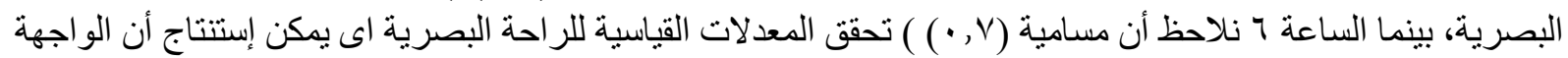

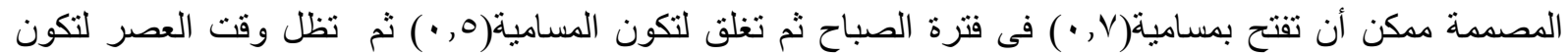

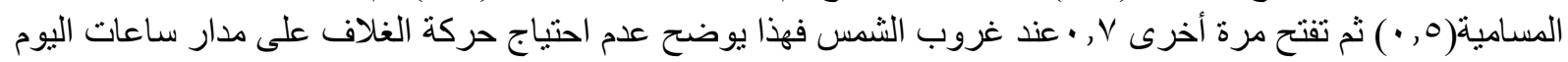

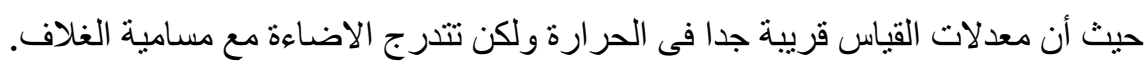

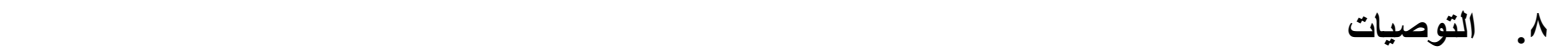

$$
\begin{aligned}
& \text { الرجوع للطبيعة بالاتجاهات المتعددة المعترف بها وفقا لمنظمة } 3.8 \text { نظر القدرة تكيفها مع المناخ و العو امل الدحيطه لتصميم }
\end{aligned}
$$

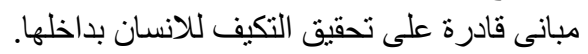

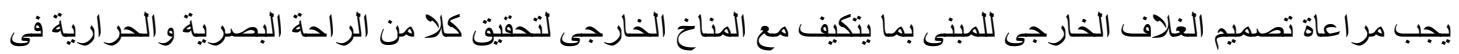

$$
\begin{aligned}
& \text { المبانى المعمارية وخاصة المبانى التعليمية. }
\end{aligned}
$$

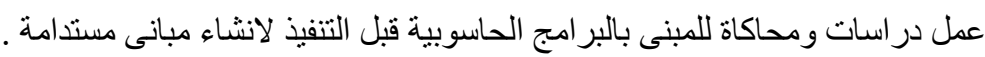

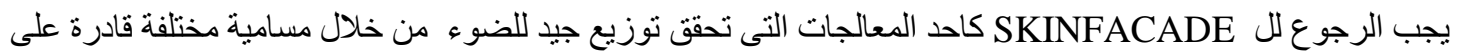

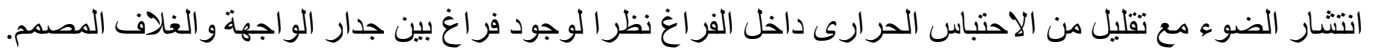

\section{REFERENCES}

[1] Pathak, S. (2019). Biomimicry:(Innovation Inspired by Nature). International Journal of New Technology and Research (IJNTR), 5(6), 34-38.

[2] Standard, A. S. H. R. A. E. (1992). 55, Thermal environmental conditions for human occupancy. American Society of Heating, Refrigerating and Air conditioning Engineers, 145.

[3] Ghonemy,G.(2021)." Integration of computer simulations with biomimic architecture". AL-Azhar Universty Cairo Egypt For the Degree of DOCTOR OF PHILOSOPHY

[4] Olesen, B. W., \& Parsons, K. C. (2002). Introduction to thermal comfort standards and 


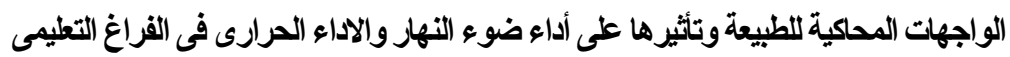

to the proposed new version of EN ISO 7730. Energy and buildings, 34(6), 537-548.

[5] Ghonimi, I. (2017). Assessing daylight performance of single vs. double skin facade in educational buildings: A comparative analysis of two case studies. Journal of Sustainable Development, 10(3), 133-142.

[6] Ghonemy, G.,et.al. (2020). BIOSIMULATION AND ITS IMPACT ON THE THERMAL COMFORT OF BUILDINGS. Journal of Environmental Science, 49(12), $1-29$.

[7] Ghonemy, G.,et.al.(2020) "Bio mimic Computational Design As A Tool For Enhancing Environmental Human Comfort In Educational Space", Publishing A Scientific Research In International Journal Of Engineering And Applied Science, Vol.67, No.6,Dec. 2020, Pp. 1495-1513 Faculty Of Engineering, Cairo University.

[8] https://comfort.cbe.berkeley.edu/ , (Accessed on 25/3/2021).

[9] https://www.solemma.com/Diva.html (Accessed on 25/3/2021).

[10] Ju, J., Bai, H., Zheng, Y., Zhao, T., Fang, R., \& Jiang, L. (2012). A multi-structural and multi-functional integrated fog collection system in cactus. Nat Commun 3: 1247.

[11] Zwieniecki, M. A., Haaning, K. S., Boyce, C. K., \& Jensen, K. H. (2016). Stomatal design principles in synthetic and real leaves. Journal of the Royal Society Interface, 13(124), 20160535.

[12] IES Daylight Metrics Committee. (2012). IES Spatial Daylight Autonomy (sDA) and Annual Sunlight Exposure (ASE), Daylight Metrics Committee. Approved Method IES LM-83-12. Illuminating Engineering Society of North America.

[13] Lee, G., Sacks, R., \& Eastman, C. M. (2006). Specifying parametric building object behavior (BOB) for a building information modeling system. Automation in construction, 15(6), 758-776.

[14] Reinhart, C. F. (2001). Daylight availability and manual lighting control in office buildings: Simulation studies and analysis of measurement. Fraunhofer-IRB-Verlag.

[15] Council, U. G. B. (2013). LEED reference guide for building design and construction. US Green Building Council.

[16] Abdelwahab, S., Rutherford, P., Mayhoub, M., \& Altomonte, S. (2019). Sensitivity Analysis on the Impact of User Control on Daylight and Energy Simulations. In IBPSA-Building Simulation 2019 International Conference..

[17] Elsamadisy, R., Sarhan, A. E., Farghaly, Y., \& Mamdouh, A. (2019). BIOMIMICRYAS A DESIGN APPROACH FOR ADAPTATION. Journal of AlAzhar University Engineering Sector, 14(53), 1516-1533.

[18] Reinhart, C. F., \& Wienold, J. (2011). The daylighting dashboard-A simulation-based design analysis for daylit spaces. Building and environment, 46(2), 386-396.

[19] Fanger, P. O. (1970). Thermal comfort. Analysis and applications in environmental engineering. Thermal comfort. Analysis and applications in environmental engineering.

[20] Nicol, J. F., \& Humphreys, M. A. (2002). Adaptive thermal comfort and sustainable thermal standards for buildings. Energy and buildings, 34(6), 563-572. 